\title{
Tarra onde, menina réa? A aspiração de /v/ no falar de Fortaleza
}

\author{
Tarra onde, menina réa? The aspiration of $/ \mathrm{v} /$ in the \\ Fortaleza spoken language variety
}

\author{
Ana Germana Pontes Rodrigues* \\ Universidade Estadual do Ceará \\ Fortaleza - Ceará / Brasil \\ Alviza Alves de Araújo** \\ Universidade Estadual do Ceará \\ Fortaleza - Ceará / Brasil
}

\section{Resumo}

À luz da Sociolinguística Variacionista, este estudo aborda a fricativa $/ \mathrm{v} /$, cuja realização ocorre tanto com [v] (manutenção) quanto com [h] (aspiração), como em [v]ai $\sim[\mathrm{h}]$ ai e ta[v]a $\sim$ ta[h]a. Com o objetivo de analisar os condicionamentos linguísticos e sociais sobre a regra em questão, selecionou-se uma amostra, constituída por 48 informantes, que foi retirada do banco de dados do Projeto Norma Oral do Português Popular de Fortaleza. A variável linguística mais importante foi o contexto fonológico subsequente: a vogal [a] foi a que apresentou maior ocorrência com a variante aspirada. Dentre os fatores sociais, os dois mais relevantes foram a faixa etária e a escolaridade. O primeiro mostra que os informantes de 50 anos ou mais favorecem a aspiração; o segundo apresenta a escolaridade de 0 a 4 anos como favorecedora do fenômeno, reforçando a tese de que

\footnotetext{
* anagermaninha@gmail.com

**aluiza.araujo@uece.br
} 
a variante aspirada é estigmatizada pelos fortalezenses nesta amostra. Tais resultados sugerem indícios de uma mudança em progresso.

\section{Palavras-chave}

Fricativa /v/; Aspiração; Sociolinguística Quantitativa; Fortaleza.

\section{Abstract}

In the light of Variationist Sociolinguistics, this study approaches the fricative $/ \mathrm{v} /$, whose realization occurs with both [v] (maintenance) and with [h] (aspiration), as in [v]ai $\sim[\mathrm{h}]$ ai ta $[\mathrm{v}] \mathrm{a} \sim \mathrm{ta}[\mathrm{h}] \mathrm{a}$. Aiming at the analyzes of the social and linguistic constraints that govern this variation, we selected a sample made up of 48 informants, from the database of the Project Oral Standard of Popular Portuguese from Fortaleza. The most important linguistic variable found was the phonological context in which the vowel [a] showed the highest occurrence with the aspirated variant. Among the social factors, the two most important were age and schooling. The former implies that informants above 50 years old influence aspiration, the latter indicates that within 0 to 4 years of schooling as favor the phenomenon, supporting the argument that the aspirated variant is stigmatized by speakers from Fortaleza. Such results suggest evidence of a change in progress.

\section{Keywords}

Fricative /v/; Aspiration; Quantitative Sociolinguistics; Fortaleza. 


\section{INTRODUÇÃO}

$\mathrm{E}$ ste trabalho aborda, no falar fortalezense, a realização de /v/ como fricativa glotal tendo por base uma análise de oitiva, processo esse referido aqui como aspiração, que tanto ocorre no contexto de início absoluto de palavra quanto na posição intervocálica, como ilustram as formas linguísticas [h] ou e no[h] ela, colhidas dos nossos dados.

$\mathrm{Na}$ fase de coleta dos dados, ao ouvirmos inquéritos do NORPOFOR (Projeto Norma Oral do Português Popular de Fortaleza), encontramos variação semelhante com o uso das fricativas /s, z, J, 3/, tanto em posição de ataque silábico quanto de coda, como exemplificado em: negó [s] io de meia $\sim$ nego[h]o de mêa; ca[z]a ca[h]a; me[z]mo me[h]mo; ma[J]tigar $\sim$ ma[h]tigar; a gente - a [h]ente; mai[s] fácil mai[ $\varnothing]$ fácil; é me[z]mo é me[ $\varnothing]$ mo; dois tipo[3] de $\sim$ dois tipo[ $\varnothing]$ de.

Assim, observamos que /v/ pode se realizar como [v] ou como [h] (aspiração); e /s z $\int 3 /$ se realizam como $\left[s, z, \int, 3\right]$, como [ $\left.\varnothing\right]$ (apagamento) ou como [h, h] (aspiração). No entanto, no presente estudo, resolvemos restringir nossa análise apenas para os contextos de /v/.

O fenômeno analisado aqui tem registros, no falar cearense, desde 1937, e continuou sendo relatado, inclusive, por pesquisadores de outros estados, principalmente do Nordeste, que encontraram essa mesma realização variável em suas cidades.

Nesta pesquisa, adotam-se os pressupostos teórico-metodológicos da Sociolinguística Quantitativa, que procura sistematizar os dados linguísticos, descreve a estrutura e a mudança da língua dentro de um contexto social e estabelece relações entre os fatores linguísticos e extralinguísticos.

Este estudo, tendo o objetivo de examinar as variáveis linguísticas (contexto fonológico precedente, contexto fonológico seguinte, tipo de sílaba, tonicidade, status morfológico do segmento, dimensão do vocábulo, classes de palavras, frequência de uso e grupo fônico) e sociais (gênero/sexo, faixa etária, escolaridade e registro) que atuam sobre a aspiração, nos proporcionou averiguar, 
com base nos resultados obtidos, se o fenômeno se encontra em variação estável ou se há indícios de uma mudança em progresso. Para efeito de comparação com as nossas análises, teremos como base também os resultados obtidos em outros trabalhos de natureza variacionista a respeito da aspiração de $/ \mathrm{v} /$.

Com base nessas observações que fizemos a respeito da realização variável de $/ \mathrm{v} /$, deparamo-nos com as seguintes questóes: qual(is) o(s) fator(es) favorece $(\mathrm{m})$ a aspiração de /v/?; qual o papel de cada variável linguística e extralinguística sobre a realização do fenômeno em estudo?

Para responder a tais questionamentos, formulamos, antes da coleta dos dados, as seguintes hipóteses, com base na literatura:

- os fatores que favorecem a realização de /v/ como aspirada são: entre as variáveis extralinguísticas, a escolaridade, a faixa etária e o registro e, entre os fatores linguísticos, os contextos fonológicos antecedente e subsequente, frequência de uso e status morfológico do segmento;

- os contextos fonológicos circundados pela vogal /a/ atuam de forma positiva sobre a regra em estudo;

- quanto maior a frequência de uso do item lexical, maior será a possibilidade de ocorrer a forma aspirada;

- os morfemas gramaticais, em especial os que contêm o pretérito imperfeito do indicativo com a forma /ava/, favorecerão mais a aplicação da regra do que os morfemas lexicais;

- os fatores tonicidade, tipo de sílaba e dimensão do vocábulo não são relevantes para o fenômeno estudado;

- o fator escolaridade exerce influência na aspiração das fricativas, pois quanto menor o grau de escolaridade, maior o emprego da regra em estudo;

- a faixa etária dos falantes exerce influência na realização variável do fenômeno, pois quanto menor a faixa etária, maior será a ocorrência do fenômeno;

- quanto menor o grau de formalidade, maior será a aspiração e quanto maior o grau de formalidade maior será a aplicação da regra analisada.

- a variável gênero/sexo não exerce influência sobre a regra em pauta;

Para a nossa análise, utilizamos uma amostra constituída por 48 informantes, extraída do Projeto Norma Oral do Português Popular de Fortaleza (NORPOFOR), com o objetivo de verificarmos a atuação de variáveis linguísticas e extralinguísticas sobre a realização variável de /v/. 
A escolha desse tema justifica-se, primeiramente, pelo fato de o aspecto fonético ser um dos que mais rapidamente revelam as variações linguísticas, tanto as diatópicas quanto as diastráticas ${ }^{1}$. Também, por estarmos descrevendo a língua em uso, este trabalho pode contribuir para o ensino de língua materna e de língua estrangeira, ao colaborar para o desenvolvimento da competência comunicativa e ao proporcionar a professores e alunos um melhor conhecimento da diversidade linguística local. Ademais, esta investigação poderá auxiliar os profissionais da indústria cultural, proporcionando-lhes este tipo de representação do falar cearense.

Esta investigação está organizada da seguinte forma: a primeira parte, que é esta introdução, apresenta o objeto de estudo, o arcabouço teóricometodológico, a justificativa, as hipóteses e os objetivos da investigação; a segunda parte traz a recensão dos estudos variacionistas, no português brasileiro, sobre o fenômeno em estudo; a terceira seção detalha a metodologia, exibindo o corpus utilizado, a nossa amostra, o perfil dos informantes e as variáveis controladas; a quarta parte expõe os resultados obtidos e a análise dos dados; e a última parte apresenta as conclusões.

\section{ESTUDOS VARIACIONISTAS SOBRE A ASPIRAÇÃO DA FRICATIVA /V/ NO PORTUGUÊS DO BRASIL}

Nesta seção, apresentaremos os trabalhos de natureza variacionista que abordaram a aspiração da fricativa $/ \mathrm{v} /$ no português brasileiro. Roncarati e Uchoa (1988) e Roncarati (1999) tratam do fenômeno no falar cearense; já Canovas (1991), Pelicioli (2008) e Marques (2001) descrevem a sua ocorrência em outros locais do país.

Roncarati e Uchoa (1988) e Roncarati (1999) estudam a aspiração e o apagamento das fricativas $/ \mathrm{v}, \mathrm{z}, 3 /$ na fala cearense, procurando determinar o seu contexto linguístico e pragmático, medindo também o nível de estigmatização do fenômeno, através de um teste de atitudes linguísticas. Seus resultados revelaram que, em /v/, apenas 6,85\% (104/1519) ${ }^{2}$ dos dados foram de aspiração. Esses dados foram baseados em uma pequena amostra, com dez falantes: seis homens e quatro mulheres, com escolaridade de $1^{\circ}$ (Ensino Fundamental) e $2^{\circ}$ graus (Ensino Médio) e uma informante analfabeta. A faixa etária é dividida entre criança (uma de 10 anos), adolescentes (um de 14 e outro de 15 anos), 
jovens (um de 21, outro de 22 e um de 24 anos) e adultos (um de 38, dois de 40 e um de 42 anos). Além desses fatores sociais e linguísticos, os autores procuraram isolar o efeito do léxico e dos condicionantes discursivos, efetuando um levantamento dos itens mais frequentes em cada entrevista e calculando a frequência absoluta deles (dos aspirados e não aspirados).

Os resultados dos fatores sociais revelaram que, quanto à escolaridade, $\mathrm{o}$ índice de aspiração de $/ \mathrm{v} /\left(0,89^{3}\right)$ é menor em falantes com as séries iniciais do $1^{\circ} \mathrm{grau}$; os resultados gerais para os fonemas /v, z, $3 /$ foram: analfabetos $(0,45$ $-42 / 46), 1^{\mathrm{a}}$ a $4^{\mathrm{a}}$ série $(0,78-99 / 130), 5^{\mathrm{a}}$ a $8^{\mathrm{a}}$ série $(0,30-161 / 235)$ e $2^{\circ}$ grau $(0,42$ - 68/97). Quanto à classe social, a aspiração é maior na classe baixa; para /v/: classe baixa $(0,66)$ e média $(0,34)$. Quanto ao sexo, o fenômeno analisado ocorre mais entre os homens $(0,51)$ do que entre as mulheres $(0,48)$, embora ambos os valores se aproximem do ponto neutro. Quanto à idade, a aspiração $\mathrm{de} / \mathrm{v} /$ tem um índice maior entre os jovens $(0,80)$; os resultados gerais dessa variável para os fonemas /v, z, 3 / foram: criança $(0,85-25 / 25)$, adolescentes $(0,28-3 / 5)$, jovens $(0,38-149 / 212)$ e adultos $(0,40-193 / 265)$.

Os fatores linguísticos analisados foram a distância da vogal tônica mais próxima ${ }^{4}$ e a qualidade vocálica. Quanto à distância da vogal tônica mais próxima, a distância antecedente 1 é a mais favorecedora da aspiração de /v/ $(0,73)$. Para exemplificar esse contexto, eles citam: "na ditadura ta[h]a pior que isso". Para as demais distâncias antecedentes $(0,2,3 \text { e } 4)^{5}$, os valores não foram relevantes. Quanto à distância da tônica seguinte, os maiores índices de aplicação da regra ocorreram nas distâncias $4(0,68), 1(0,61), 3(0,57)$ e 5 $(0,55)^{6}$. Quanto à qualidade vocálica, a forma aspirada de $/ \mathrm{v} /$ obteve índices mais altos com a vogal /a/, tanto antecedendo $(0,78-66 / 471)$ quanto sucedendo $(0,64-72 / 405)$ o segmento; em posição intervocálica, o grupo /ava/ obteve os índices mais altos $(0,85-62 / 245)$. Os autores ressaltam ainda que

o agrupamento $\mathrm{a}+\mathrm{a}$, com o segmento em estudo em posição intervocálica, foi o que registrou o índice mais alto de enfraquecimento, considerando-se a totalidade dos contextos de quaisquer vogais em quaisquer posiçōes (pré, pós e intervocálica). (RONCARATI; UCHOA, 1988, p. 43).

Em relação à fricativa $/ \mathrm{v} /$, os autores avaliaram ainda os fatores linguísticos: posição do segmento (início e interior de palavra) e marca de desinência verbal 
(formas em /ava/, outras formas verbais e outras formas não verbais). Para o primeiro, o maior índice ficou com a posição de interior de palavra $(0,60$ 75/799); enquanto, em início de palavra, o índice foi de 0,39 (29/720). Os autores comentam que esse resultado favorece as formas do imperfeito em / ava/. Quanto à marca de desinência verbal, o maior índice constatado foi, realmente, com as formas em /ava/ (0,84-62/241); em seguida, foram outras formas verbais $(0,37$ - 30/695) e outras formas não verbais $(0,27-12 / 583)$.

Esse resultado fez com que os autores buscassem medir a frequência de uso ${ }^{7}$, associando-o ao grau de favorecimento ou não da aspiração, considerando que o fenômeno poderia ser mais bem explicado à luz do difusionismo lexical ${ }^{8}$. Para fazer esse levantamento lexical, os autores incluíram, além das dez entrevistas: uma de IMP (Interação Médico-Paciente), gravada no Instituto Psiquiátrico do Ceará, com três participantes, e quatro gravaçōes de falantes do interior, pertencentes ao Projeto ALECE (Atlas Linguístico do Ceará). Os falantes do interior possuíam as seguintes características: três mulheres, uma de 41 anos, da classe alta; outra, de 9 anos, da classe baixa e a terceira, de 46 anos, da classe média; e um homem, de 45 anos, da classe média?.

Os autores consideraram como itens "mais frequentes" tanto aqueles que seriam muito produzidos pela totalidade dos falantes da amostra quanto um item que fosse muito frequente no léxico de um falante, incluindo o seu uso interiorano ou citadino ${ }^{10}$. Além disso, esses autores elaboraram uma espécie de verbete para cada item lexical, contendo suas realizações plenas (manutenção) e aspiradas. Ao final, foi organizado um dicionário para cada fricativa $(/ \mathrm{v} /, / \mathrm{z} /$ e /3/) e foi feito um cálculo das frequências globais dos informantes.

Nos resultados dessa pesquisa, o morfema do imperfeito foi selecionado em primeiro lugar. Os verbos com esse morfema são os mais frequentes no léxico de todos os falantes do corpus por eles analisado: com os fortalezenses da amostra básica (dez falantes), a aspiração atingiu 25,86\%; com os três participantes da Interação Médico-Paciente (IMP), esse índice foi de 68,29\%; e nos quatro falantes do interior, esse valor foi ainda maior, $77,77 \%$. Além disso, comprovam ainda que quanto maior a frequência de uso do verbo, maior será a probabilidade de ocorrer a aspiração, como aconteceu com os verbos "ta[h]a" (23 ocorrências na amostra básica) e "queixa[h]a" (três ocorrências na IMP). Em segundo lugar, vieram os verbos "gosta[h]a" (dez ocorrências na amostra básica), "brinca[h]a", 
"toma[h]a" e "fica[h]a" (estes três no interior do Ceará), seguidos por "da[h]a" (seis ocorrências na amostra básica).

As realizações da fricativa / $/$ que foram produzidas como aspiradas nas formas do verbo "ir" apareceram em segundo lugar, registrando-se 18,43\% (47/255) das ocorrências, nas formas: "vou", "vi", "vamos" e "vá". Em seguida, com as formas do verbo "ver" ([h]iu, [h]ia, [h]imos) e "vir" ([h]em, [h] eio, [h] inha, [h] iemo(s)), também foi documentada a realização de /v/ como aspirada, na IMP (Interação Médico-Paciente) e nas amostras interioranas (do ALECE). Além dos verbos, outras expressões bastante utilizadas foram a locução adverbial "às [h] ezes" e a locução interjetiva "A[h]e Maria".

Sobre a correlação entre categoria lexical (gramatical e lexical) ${ }^{11}$ e a frequência de uso do léxico, verificou-se que a aspiração tende a ser maior sobre os elementos do enunciado que só têm sentido em relação à estrutura gramatical, nos quais se incluem os morfemas gramaticais. Os morfemas lexicais, por sua vez, portadores de conteúdo informacional, são mais resistentes à aspiração. Os autores também procuraram medir o nível de informalidade e, embora não tenham conseguido confirmar em seus dados, acreditam que exista uma relação entre aspiração e informalidade.

Por fim, o teste de atitudes que os autores aplicaram revelou que: a situação de fala informal favorece a regra estudada; a variante aspirada é uma marca masculina (sinalizaria "manifestação de 'macho"); os adultos aspiram mais as fricativas; há uma forte correlação entre nível de estigmatização e origem do falante (as mais estigmatizadas são atribuídas a falantes interioranos); a frequência de uso de um item lexical e a aceitação dos itens aspirados caminham juntas.

Analisando os trabalhos sobre a realização das fricativas em outros estados do Brasil, encontramos o trabalho de Canovas (1991) sobre o falar de Salvador. Sua pesquisa analisa a realização de /S/ pós-vocálico e de /v, z, 3/ em ataque silábico. Sua amostra constituiu-se de 45 informantes, distribuídos desta forma: escolaridade ( $1^{\circ}, 2^{\circ}$ e $3^{\circ}$ graus) e idade (13-20, 21-45 e 46-70 anos). Ela não levou em consideração a variável sexo por constatar que, em seus dados (assim como na maioria de outros estudos linguísticos), as mulheres mostram um comportamento linguístico conservador. As gravações foram feitas pela autora e tinham um caráter semi-informal. Além dessas, ela também coletou entrevistas televisivas de 79 informantes de nível superior, com idade entre 25 a 60 anos, sendo apenas oito do sexo feminino, em situações de fala formal. 
Segundo a autora, em /v, z, 3/, o processo de aspiração encontra-se em fase embrionária. $\mathrm{O}$ uso da forma padrão é quase unânime, com 4,13\% de uso da variante aspirada (72/1744). A fricativa / $/$ t teve resultados diferentes, pois os falantes mais escolarizados, de $3^{\circ}$ grau, foram os que mais aspiraram $(5,73 \%$ ou 34/593); em seguida, vêm os falantes que possuíam até o $1^{\circ}$ grau $(3,60 \%$ ou $21 / 583)$ e, por último, os que tinham o $2^{\circ}$ grau completo $(0,52 \%$ ou $3 / 568)$. Quanto à idade, são os mais idosos que mais realizam a variante aspirada (4,05\% ou 25/617), seguidos dos de 21 a 45 anos (3,42\% ou 21/613) e dos de 13 a 20 anos (2,33\% ou 12/514). A respeito da ocorrência com as formas em /ava/, Canovas (1991) verifica que, em Salvador, elas não foram relevantes o suficiente para aumentar o índice de aspiração.

Quanto aos fatores linguísticos, em relação a /v/, a autora controlou apenas a tonicidade e verificou que as ocorrências aspiradas de $/ \mathrm{v} / \mathrm{em}$ início de sílaba são bem mais frequentes em sílabas átonas [-ac] $(56 / 970=5,77 \%)$ do que em sílabas tônicas [+ac] $(2 / 774=0,25 \%)$.

Ainda em Salvador e quase vinte anos depois, Pelicioli (2008) trata especificamente da aspiração das fricativas na fala dessa cidade. Seu corpus foi constituído por oito inquéritos experimentais do projeto $\mathrm{ALiB}$, distribuídos igualmente entre faixa etária (I - 20 a 30 anos; II - 46 a 61 anos), gênero (masculino e feminino) e nível de escolaridade (fundamental e universitário).

A aspiração de /v/, que não fora rodada no Varbrul, obteve 48 ocorrências, sendo o sufixo do imperfeito do indicativo /ava/ o que aparece na maioria dos casos ( $88 \%$ ou $42 / 48)$; em seguida, aparecem flexôes do verbo "ir" (10\% ou $5 / 48)$ e a palavra "inclusive" ( $2 \%$ ou $1 / 48$ ). Nas variáveis sociais, Pelicioli (2008) obteve resultados bastante semelhantes aos de Canovas (1991), pois, em relação à escolaridade, os informantes de nível universitário alcançaram 52,1\% (25/48) das realizações aspiradas de $/ \mathrm{v} /$, enquanto os de nível fundamental ficaram com $47,9 \%$ (23/48) das ocorrências. Em relação à idade, o autor também confirmou os resultados de Canovas (1991): os mais idosos (de 46 a 61 anos) aspiram mais a fricativa /v/ (58,3\% ou 28/48), do que os falantes de 20 a 30 anos $(41,7 \%$ ou 20/48).

Sobre o falar pessoense, no estado da Paraíba, Marques (2001) trata da aspiração do fonema /v/. Ela utilizou todo o corpus do projeto VALPB (Variação Linguística no Estado da Paraíba), ou seja, 60 informantes, sendo 30 homens e 30 mulheres, 20 de cada faixa etária (15-25 anos, 26-49 anos e mais de 50 
anos), e 12 para cada divisão em anos de escolarização (0-4 anos, 5-8, 9-11 e mais de 11 anos). A ocorrência de /v/ nessa comunidade dá-se de duas formas: realização plena e aspirada. Marques dividiu seus dados em dois arquivos: arquivo 1, composto pelos contextos em que a vogal /a/ está circundando /v/; arquivo 2, formado pelos demais contextos em que $/ \mathrm{v} /$ está precedido e sucedido por vogais variadas (por exemplo: $/ \mathrm{i} /+/ \mathrm{v} /+/ \mathrm{e} /{ }^{12}=$ tivesse).

Assim, seus resultados revelaram que, no arquivo 1, quanto ao status morfológico do segmento, os morfemas lexicais tendem a conservar a realização plena $(0,12)$, enquanto os morfemas não lexicais ${ }^{13}$ são mais favoráveis à aplicação do fenômeno, ou seja, da aspiração $(0,57)$. Quanto à dimensão do vocábulo, verificou-se que os dissílabos são fortes favorecedores da regra $(0,66)$ ao lado dos monossílabos $(0,54)^{14}$. Quanto às classes de palavras, os resultados indicaram que os verbos foram os que mais favoreceram a aspiração $(0,53)$.

No arquivo 2, a posição/tonicidade do segmento foi o fator selecionado como o mais relevante, resultando que a tônica medial $(0,73)$ e a pós-tônica $(0,71)$ são as que mais favorecem a variante aspirada. Quanto ao contexto fonológico seguinte e precedente, constatou-se que /v/, quando sucedido pela vogal /a/, alcança o índice de 0,76 (para a regra) e, "quando /v/ está antecedido por uma vogal média e sucedido por um /a/, ou antecedido por /a/ e seguido por uma vogal nasal, a probabilidade de variação é bastante positiva $(0,77$ e 0,68$)$." (MARQUES, 2001, p. 70). Em relação às classes de palavras, novamente os verbos foram os mais relevantes para a aspiração $(0,60)$ em razão, sobretudo, da forma do imperfeito.

Com relação aos fatores sociais, só foram selecionados os fatores do arquivo 1. Quanto aos anos de escolarização, verificou-se que quanto maior o grau de escolaridade, menor será a aspiração (até 8 anos de escolarização, os pesos variaram de 0,56 a 0,59$)$. Em relação à faixa etária, apenas os indivíduos de 26 a 49 anos tiveram um valor relevante $(0,58)$; os que tinham mais de 50 anos tiveram um valor abaixo do ponto neutro, de 0,47 . No tocante ao sexo, as mulheres foram as maiores favorecedoras à realização aspirada $(0,54)$. Por fim, o resultado global da ocorrência dessas duas variantes presentes no corpus mostrou que o índice de aplicação da regra é de apenas 0,13 contra $0,88 \mathrm{da}$ realização da fricativa labiodental.

Enfim, os estudos apresentados nessas seções contribuíram, principalmente, para verificarmos a existência da aspiração em algumas localidades do Brasil e para 
fazermos o levantamento das principais variáveis que estariam condicionando o fenômeno em estudo (aspiração). No Ceará, os fatores mais relevantes foram a frequência de uso do item lexical, a classe gramatical, o contexto fonológico, a categoria lexical (palavra gramatical e lexical) e o registro (informal). Em Salvador (Bahia), foram levados em consideração praticamente os mesmos fatores sociais (e um linguístico: a tonicidade). Constatou-se também que a aspiração, ao contrário do Ceará, não seria um estereótipo, mas apenas uma espécie de indicador, visto que ocorre em todos os grupos socioeconômicos e etários. Já em João Pessoa (Paraíba), ao serem analisados contextos mais específicos de $/ \mathrm{v} /$, verificou-se que a escolaridade, a faixa etária e o sexo também estariam influenciando a ocorrência da regra em questão.

Portanto, nesses estudos, tanto fatores linguísticos quanto sociais têm influência sobre o fenômeno. No entanto, no Ceará, percebemos que há uma predominância de fatores linguísticos associados a um forte fator social, diatópico, a marca regional do estado do Ceará, em consonância com Aragão (2009).

\section{METODOLOGIA}

A nossa amostra foi extraída do acervo sonoro do banco de dados do Projeto Norma Oral do Português Popular de Fortaleza (NORPOFOR) ${ }^{15}$, desenvolvido com o objetivo de armazenar e disponibilizar material linguístico representativo do falar popular dos fortalezenses. As gravaçōes deste corpus foram coletadas entre agosto de 2003 e julho de 2006 (ARAÚJO, 2011). Trata-se, portanto, do banco de dados de fala popular fortalezense mais atual que temos.

A escolha desse corpus deve-se ao fato de esse Projeto atender às exigências da pesquisa sociolinguística quantitativa no que diz respeito aos critérios de seleção dos informantes e de coleta de dados. Segundo Araújo (2011), todos os informantes do NORPOFOR apresentam o seguinte perfil:

São fortalezenses natos ou vieram morar nesta cidade com, no máximo, cinco anos de idade; - possuem pais cearenses; nunca se ausentaram de Fortaleza por um período superior a dois anos consecutivos; mantêm residência fixa na capital cearense. Estes critérios foram adotados com o objetivo de neutralizar a interferência dos falares de outras regiōes. (ARAÚJO, 2011, p. 838). 
O NORPOFOR é constituído por 198 informantes, estratificados de acordo com o gênero/sexo ${ }^{16}$ (masculino e feminino), a faixa etária ( 15 a 25 anos; 26 a 49 anos; e a partir dos 50 anos), a escolaridade ( 0 a 4 anos; 5 a 8 anos; e 9 a 11 anos) e o tipo de registro (Diálogo entre Informante e Documentador-DID; Diálogo entre dois Informantes-D2; e Elocução Formal-EF). Nesta pesquisa, utilizamos 48 informantes deste banco de dados, organizados em função de ambos os gêneros/sexos, das três faixas etárias, de dois tipos de registro (DID e D2) e de dois níveis de escolaridade (0 a 4 e 9 a 11 anos). Desconsideramos a escolaridade intermediária (de 5 a 8 anos), pois, com base na literatura (cf. MARQUES, 2001; PELICIOLI, 2008), os resultados mais relevantes foram encontrados nas faixas extremas. Selecionamos o DID e o D2, porque os dois primeiros são os estilos menos tensos, ao contrário das gravaçôes do tipo EF que eram mais tensas, pois incluíam os cultos religiosos, aulas e palestras, e tínhamos o interesse de analisar o fenômeno no falar mais natural possível.

As entrevistas do tipo DID e D2 eram realizadas no dia, horário e local determinados pelos entrevistados. Com relação ao DID, as perguntas feitas pelo entrevistador ao entrevistado eram curtas e claras, com a finalidade de fazer com que o entrevistado falasse o máximo possível. Essas perguntas não eram previamente formuladas, como se fosse um questionário, mas sim feitas no decorrer da entrevista. Os relatos de assuntos que mais interessavam ao entrevistado eram bastante explorados pelo documentador, fazendo com que o informante acabasse esquecendo que sua fala estava sendo gravada e se sentisse mais à vontade, procurando neutralizar, assim, o paradoxo do observador. Segundo Labov ([1972] 2008), essa seria a situação em que o pesquisador deveria coletar o vernáculo do informante, ou seja, uma fala mais espontânea.

No D2, os documentadores quase nunca interagiam com os participantes. Registramos um ou outro inquérito em que o documentador, presente no local do diálogo, interferia solicitando que os participantes continuassem conversando, dando ideias sobre outros assuntos que eles poderiam abordar. No entanto, na maioria dos inquéritos de $\mathrm{D} 2$, não houve essa interrupção, pois o objetivo era fazer com que os informantes ficassem mais à vontade e travassem um diálogo livre de monitoramentos.

Todas essas entrevistas foram realizadas com um gravador analógico Sony TCM - DV e três gravadores analógicos CSR (Slimline Cassete Recorder with ATRS WG223 - TR). Posteriormente, todas as gravações foram digitalizadas, 
com o auxílio do programa Sound Forge 9.0. A taxa de amostragem foi de 44 $100 \mathrm{~Hz}$.

Para cada célula da nossa amostra, há dois informantes. Nenhum outro estudo sobre o fenômeno analisado apresenta uma amostra tão balanceada quanto esta, considerando as mesmas variáveis sociais para a comunidade de fala que ora analisamos. (ver TAB. 1).

TABELA 1

Distribuição dos informantes desta amostra por gênero/sexo, idade, tipo de registro e escolaridade

\begin{tabular}{|l|c|c|c|c|c|c|c|c|}
\cline { 2 - 9 } \multicolumn{1}{c|}{} & \multicolumn{9}{|c|}{ Gênero/Sexo } \\
\cline { 2 - 9 } \multicolumn{1}{c|}{ Tipo de registro } & \multicolumn{4}{c|}{$\begin{array}{l}\text { Diálogo entre } \\
\text { Informante e } \\
\text { Documentador }\end{array}$} & $\begin{array}{c}\text { Diálogo entre } \\
\text { Dois } \\
\text { Informantes }\end{array}$ & $\begin{array}{l}\text { Diálogo entre } \\
\text { Informante e } \\
\text { Documentador }\end{array}$ & $\begin{array}{c}\text { Diálogo entre } \\
\text { Dois } \\
\text { Informantes }\end{array}$ \\
\hline $\begin{array}{c}\text { Escolaridade } \\
\text { Faixa etária }\end{array}$ & $0-4$ & $9-11$ & $0-4$ & $9-11$ & $0-4$ & $9-11$ & $0-4$ & $9-11$ \\
\hline 15 a 25 anos & 2 & 2 & 2 & 2 & 2 & 2 & 2 & 2 \\
\hline 26 a 49 anos & 2 & 2 & 2 & 2 & 2 & 2 & 2 & 2 \\
\hline 50 em diante & 2 & 2 & 2 & 2 & 2 & 2 & 2 & 2 \\
\hline
\end{tabular}

Os informantes da nossa amostra são provenientes de 25 bairros, distribuídos entre as seis regionais ${ }^{17}$ que existem na cidade de Fortaleza, o que nos proporciona, embora de forma desigual, uma representação geográfica de toda a área da cidade. A maior parte dos nossos informantes mora em bairros pertencentes ao setor oeste da cidade, cuja renda média por pessoa é bastante baixa. Podemos perceber que cinco dos nossos 48 informantes (10,4\%) estão localizados nos bairros Bom Jardim e Farias Brito. Em terceiro lugar, com quatro informantes (8,3\%), aparece o bairro Álvaro Weyne.

De acordo com o censo de 2000 do $\mathrm{IBGE}^{18}$, os bairros mais ricos de Fortaleza (com renda média entre R \$ 1.566,29 e R \$ 4.288,36), estão concentrados no leste e no sudeste, incluindo o Centro da cidade (R \$ 1.306,06); são eles: Meireles ( $\mathrm{R}$ \$ 4.288,36), Guararapes ( $\mathrm{R}$ \$ 3.537,79), Cocó ( $\mathrm{R}$ \$ 3.437,34), Aldeota (R\$3.336,30), Estância/Dionísio Torres (R\$3.264,66), Mucuripe ( $\mathrm{R} \$ 2.796,98)$, Papicu ( $\$$ 2.220,41), Varjota $(\mathrm{R} \$ 2.167,98)$, Parque Manibura ( $\mathrm{R} \$ 2.125,68)$, Salinas $(\mathrm{R} \$ 2.125,66)$, Praia de Iracema $(\mathrm{R} \$$ $1.859,73)$, Praia do Futuro I (R\$1.616,46), Cidade dos Funcionários $(\mathrm{R} \$$ 
1.685,57), Cambeba ( $\mathrm{R} \$ 1.675,89)$, Joaquim Távora ( $\mathrm{R} \$ 1.572,94)$, Alagadiço Novo ( $\mathrm{R} \$ 1.566,29)$ e Engenheiro Luciano Cavalcante $(\mathrm{R} \$ 1.469,07)$. Apenas três bairros do setor oeste da cidade aparecem entre os que possuem renda alta: Fátima ( $\mathrm{R}$ \$2.017,22), Benfica $(\mathrm{R} \$ 1.417,93)$ e Parquelândia $(\mathrm{R} \$ 1.530,53)$.

Já os bairros com menor renda média por pessoa (entre R \$239,25 e R \$ $349,74)$ encontram-se no setor oeste, predominantemente. Segundo Matos e Neto (2003, p. 8),

São bairros antigos e novos que se misturam, nesse traçado, acompanhando o litoral (Arraial Moura Brasil, Pirambu, Cristo Redentor, Barra do Ceará e Floresta), além de prosseguir no sentido norte-sul (Autran Nunes, Genibaú, Granja Portugal, Granja Lisboa, Bom Jardim, Parque São José, Parque Santa Rosa (Apolo XI), Parque Presidente Vargas, Canindezinho e Siqueira); finalmente, mais para o sul, encontram-se: Barroso, Jangurussu e Curió.

As autoras verificam ainda que há bairros considerados pobres também no setor leste, como Cais do Porto e Vicente Pinzon, e no sudeste, como Edson Queiroz e Sabiaguaba. Outra observação importante sobre isso, feita por elas, é que:

Verifica-se uma associação direta entre níveis de escolaridade e renda. Nos bairros, onde os chefes de família apresentam níveis mais elevados de renda, eles situam-se melhor quanto à escolaridade, entre aqueles, que estudaram 15 anos e mais. Ao contrário, onde os chefes têm rendas mais deprimidas, eles, também, apresentam uma tendência maior de estarem sem instrução ou terem cursado apenas um ano de estudo. (MATOS; NETO, 2003, p. 8)

Há exceções sobre isso nos bairros Edson Queiroz e Vicente Pinzon, onde há chefes de família com mais de 15 anos de estudo e outros sem nenhuma escolarização.

Quanto à profissão/atividade dos informantes do NORPOFOR que compõem a nossa amostra, temos, com relação aos homens: aposentados (3), estudantes (2), serviços gerais (2), balconistas (2), militar, oficial de justiça, vigilante, serviços gerais (laboratório), eletricista, professor de reforço, tatuador, técnico em informática, segurança, estofador, pedreiro, auxiliar de pedreiro, 
comerciante, operário e supervisor de operações. Já as profissões/atividades das mulheres são: estudantes (6), prendas do lar (4), domésticas (3), costureiras (2), desempregadas (2), aposentada, lavadeira, professora aposentada, merendeira escolar, decoradora, gerente administrativa e cozinheira.

Para a transcrição dos inquéritos, utilizamos o Alfabeto Fonético Internacional (IPA, em inglês). De cada inquérito analisado, ouvimos os últimos 40 minutos. Entretanto, se o inquérito possuía menos de 40 minutos, desprezamos apenas os 5 primeiros minutos. No final das transcriçôes, totalizamos 21 horas 22 minutos e 54 segundos de gravações.

Por estarmos lidando com uma pesquisa de natureza fonológica, em poucos minutos de audição, já conseguimos reunir uma grande quantidade de dados. Isso acontece porque, segundo Labov ([1972] 2008, p. 140),

os sistemas fonológicos exibem o mais alto grau de estrutura interna de todos os sistemas linguísticos e, com isso, oferecem ao pesquisador uma extensa série de resultados paralelos e convergentes.

Foram transcritos, foneticamente, os itens lexicais que continham [v] e [h] desprezando-se os 20 primeiros minutos de gravação, pois acreditamos que, após certo tempo de entrevista, o informante não esteja mais monitorando tão rigorosamente a sua fala diante do gravador.

Nesta pesquisa, as variáveis independentes - linguísticas e extralinguísticas - foram estabelecidas com base na literatura e na audição dos inquéritos. A seguir apresentaremos cada uma dessas variáveis, ilustrando cada um dos seus fatores com ocorrências da nossa amostra.

Entre as variáveis linguísticas, temos:

a) Contexto fonológico precedente

Tanto o contexto fonológico precedente quanto o contexto fonológico subsequente podem exercer muita influência em relação ao uso da variante aspirada. Trata-se da noção de direcionalidade, com base na qual podemos dizer se um fonema possui mais afinidade com o som que o precede ou com o que o sucede. Por isso, observaremos aqui todos os elementos que circunvizinham o fonema /v/ e que podem influenciar na sua realização aspirada. Outros trabalhos que pesquisaram sobre a realização aspirada de /v/ e que utilizaram essas variáveis 
foram: Roncarati e Uchoa (1988), Marques (2001) e Aragão (2009). Abaixo, ilustramos cada um dos contextos analisados ${ }^{19}$ :

- [a]: na /v/ida (Inq. 06); chega/v/a (Inq. 06)

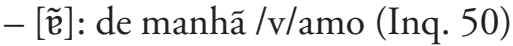

- [e]: você/v/ai (Inq. 06); de/v/ia (Inq. 06)

- [E]: é/v/ocê (Inq. 06); e/v/itá (Inq. 10)

- [ẽ]: não há ocorrência na amostra

- [i]: de /v/éa (Inq. 06); ti/v/esse (Inq. 06)

- [ĩ]: pra mim /v/ê (Inq. 50); in/v/erno (Inq. 36)

- [j]: mai /v/elho (Inq. 06); noi/v/o (Inq. 06)

- [o]: vô /v/oltá (Inq. 23); no/v/o (Inq. 06)

$-[0]:$ no/v/a (Inq. 06)

- [ō]: bombom /v/inte (Inq. 36); con/v/ênio (Inq. 67)

- [u]: pelo /v/ício (Inq. 06); chu/v/a (Inq. 95)

- [ũ]: num /v/olta (Inq. 06); cun/v/eØsa (Inq. 95)

- [w]: eu /v/ô (Inq. 06); Ál[v] uro Weyne (Inq. 94)

- Consoante: às /v/eiz $\emptyset$ (Inq. 95); sir/v/iço (Inq. 46)

- Pausa: \#/v/amoØ (Inq. 06)

b) Contexto fonológico subsequente

A seguir, ilustramos cada um dos segmentos subsequentes apresentados:

- [a]: /v/ai (Inq. 06); gosta/v/a (Inq. 06)

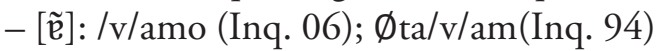

- [e]: /v/ê (Inq. 06); gu/v/erno (Inq. 46)

- [E]: /v/éi (Inq. 95); cun/v/eØsa (Inq. 95)

- [ẽ]: /v/em (Inq. 95); con/v/ento (Inq. 129)

- [i]: /v/ida (Inq. 06); vi/v/e (Inq. 06)

- [ĩ]: /v/inte (Inq. 06); no/v/im (Inq. 129)

- [o]: /v/ô (Inq. 06); fa/v/ô (Inq. 06)

- [0]: /v/olta (Inq. 06); de/v/óve (Inq. 10) 
- [o]]: /v/ontade (Inq. 50); I/v/onete (Inq. 36)

- [u]: /v/ucê (Inq. 06); no/v/o (Inq. 06)

- [ũ]:/v/ũmitanØo (Inq. 94)

- [j]: Flá/v/ia (Inq. 143)

c) Tipo de sílaba

A variável tipo de sílaba foi escolhida por supormos que o fato de uma sílaba ser travada ou livre poderia influenciar na ocorrência do fenômeno. A seguir, ilustramos cada fator:

- Travada (com presença de coda): /v/olta (Inq. 06); ser/v/iço (Inq. 06)

- Não travada (sem coda): /v/ida (Inq. 06); no/v/o (Inq. 06)

d) Tonicidade

As pesquisas, em geral, têm revelado que as sílabas tônicas, por possuírem um traço mais saliente, são mais suscetíveis a variações. Assim, verificaremos essa hipótese proposta pela literatura. Outros trabalhos que pesquisaram a aspiração de /v/ e que utilizaram essas variáveis foram: Marques (2001) e Canovas (1991). Os fatores são ilustrados abaixo:

- Tônica: /v/amo (Inq. 06); de/v/ia (Inq. 06)

- Pré-tônica: /v/ontade (Inq. 50); e/v/itá (Inq. 10)

- Pós-tônica: leva/v/a (Inq. 06)

e) Status morfológico do segmento

Embora estejamos analisando variáveis fonológicas, também investigaremos se o status morfológico do segmento exerce alguma influência para a ocorrência do fenômeno em análise, se a aspiração se dá mais nos morfemas lexicais ou nos gramaticais nos quais elas estão presentes. Por exemplo, são encontradas muitas ocorrências do fenômeno em análise no morfema verbal de pretérito imperfeito (-va), em verbos de primeira conjugação /ava/. Outras pesquisas que mediram a influência dessa variável para a aspiração de /v/ foram 
a de Roncarati e Uchoa (1988) e a de Marques (2001). Abaixo, ilustramos cada fator:

- Morfema lexical: la/v/ar (Inq. 06)

- Morfema gramatical: gosta/v/a (Inq. 06)

f) Dimensão do vocábulo

A variável dimensão do vocábulo será analisada para verificar se a extensão dele teria alguma influência sobre o fenômeno. A maior parte das pesquisas aponta que quanto mais extenso for o vocábulo, maior será a aspiração. Outra pesquisa que incluiu essa variável em suas análises foi a de Marques (2001). A seguir, ilustramos cada fator:

- Monossílabo: /v/ai (Inq. 06)

- Dissílabo: /v/amos (Inq. 67); ti/v/é (Inq. 06)

- Trissílabo ou maior: /v/iolência (Inq. 94); le/v/aram (Inq. 06)

g) Classes de palavras

A variável classes de palavras do vocábulo poderá influenciar ou não o uso da variante aspirada. As pesquisas de Roncarati e Uchoa (1988), Marques (2001) e Alencar (2007) também verificaram a influência dessa variável. A seguir, ilustramos os fatores:

- Nomes: /v/ida (Inq. 06); cutu/v/elo (Inq. 06)

- Verbos: /v/ô (Inq. 06); fala/v/a (Inq. 06)

- Interjeições: /v/ixe (Inq. 50); A/v/e Maria (Inq. 95)

h) Grupo fônico

Analisamos a variável grupo fônico a fim de separarmos dois contextos intervocálicos de /v/ que se comportavam de forma bem diferente, com relação ao fenômeno examinado, nas gravações ouvidas por nós e em outras pesquisas que apresentaram essa mesma peculiaridade (RONCARATI; UCHOA (1988), 
CANOVAS (1991), MARQUES (2001), ALENCAR (2007) e PELICIOLI (2008)). Seguem ilustraçôes de cada fator analisado:

- Palavras com /ava/ (verbos e não verbos): pega/v/a(Inq. 06); ca/v/alo (Inq. 111) - Palavras sem /ava/ (verbos e não verbos): ti/v/esse (Inq. 06); cutu/v/elo (Inq. 06)

i) Frequência de uso do segmento

A variável frequência de uso do segmento, por sua vez, leva em consideração a hipótese proposta por Roncarati e Uchoa (1988) de que o fenômeno estaria lexicalmente condicionado, pois quanto mais determinada palavra precisar ser utilizada maior será a aspiração de /v/. No entanto, utilizamos critérios diferentes dos desses autores.

Inicialmente, deixamos para codificar essa variável após todas as outras terem sido codificadas na nossa amostra. Em seguida, fizemos uma contagem de cada palavra que aparecia em nossos dados para, depois, podermos agrupá-la ou não a outras que se modificavam apenas em algumas flexões. Por exemplo, num mesmo grupo, reunimos as palavras: "volta - volto - volte - voltam - voltá - voltava - voltando - voltamo(s) - voltaram - voltado - voltarão - voltasse - voltei - voltô". Elas, juntas, contabilizaram 148 ocorrências (aspiradas ou não). No entanto, nem todas as flexões de um mesmo verbo ficaram reunidas num mesmo grupo, pois possuíam características fonológicas bem diferentes. Exemplos disso são os verbos "vem" (com 131 ocorrências) e "vinha(m)" (com 86 ocorrências).

Por último, com o número de cada grupo de palavras em mãos, pudemos reuni-las a partir de intervalos estabelecidos de acordo com o número total que encontramos em cada contexto. Por exemplo: para o contexto de /v/ em início de palavra, obtivemos 998 realizações para a palavra com maior ocorrência ("vai"), por isso a classificamos como um termo extremamente usual; o fator que viria em segundo lugar, termos muito usuais, passaria a englobar as palavras que apresentassem um número inferior de ocorrências (neste fator, de 151480, já que o grupo de palavras que apareceu em primeiro lugar nesse segundo fator - "veze(s) - veiz(e) - veizinha - vez" - obteve 430 ocorrências); os fatores sucessores, inclusive com $/ \mathrm{v} /$ em contexto intervocálico, utilizaram esse mesmo critério. Assim como feito nos estudos relatados neste artigo, os intervalos 
apresentados a seguir não foram embasados em nenhum software, mas tomou-se como parâmetro a análise dos dados apresentados na nossa amostra. A seguir exemplificamos cada um:

- Termo extremamente frequente (de 481-1000 com /v/ em início e de 301-520 com /v/ intervocálico): /v/ai (Inq. 06); ta/v/a (Inq. 06)

- Termo muito frequente (de 151-480 com /v/ em início e de 101-300 com /v/ intervocálico): /v/ê (Inq. 06); no/v/o (Inq. 06)

- Termo frequente (de 61-150 com /v/ em início e de 61-100 com /v/ intervocálico): /v/iu (Inq. 06); chega/v/a (Inq. 06)

- Termo pouco frequente (de 21-60 em ambos os contextos): /v/iolência (Inq. 94); no/v/ela (Inq. 95)

- Termo muito pouco frequente (de 01-20 em ambos os contextos): / $/$ inho (Inq. 10); chu/v/a (Inq. 95)

Entre as variáveis sociais, controlamos:

a) Gênero/sexo

Labov (1994), ao reconhecer as diferenças linguísticas entre homens e mulheres, elaborou alguns princípios básicos sobre isso. O primeiro deles é que, normalmente, são os homens que usam mais as formas não padrão. Em contrapartida, as mulheres favorecem mais as formas de prestígio do que os homens. No entanto, na mudança, são elas que se mostram mais inovadoras, utilizando as formas novas (desde que estas sejam de prestígio) bem mais do que os homens. Esses princípios levam em consideração as atitudes sociais de cada gênero/sexo.

Quanto à utilização da terminologia "gênero" para a variável sexo, Labov (2001) explica que todas as análises de diferenciação sexual, em vez de buscarem graus de masculinidade ou feminilidade identificados socialmente, começam por separar a população em homens e mulheres, o que, muitas vezes, acaba recaindo sobre o sexo biológico do indivíduo. Ao analisar o papel de homens e mulheres sobre a mudança linguística, Labov reconhece o paradoxo do gênero: "as mulheres se conformam mais atentamente que os homens a normas sociolinguísticas que são claramente prescritas, mas se conformam [adaptam] menos que os homens 
quando não são."20 (LABOV, 2001, p. 293). Assim, as mulheres são mais sensíveis aos padrões de prestígio, e esse comportamento deve desempenhar um importante papel no mecanismo da mudança linguística. A explicação para isso é que as mulheres, por, normalmente, conversarem mais com as crianças do que os homens, durante os anos de formação das regras linguísticas com maior rapidez e eficiência, provavelmente teriam forte influência sobre o ritmo do progresso e a direção da mudança linguística.

Por isso, é importante observarmos que:

A generalização correta não é a de que as mulheres lideram a mudança linguística, mas sim que a diferenciação sexual da fala frequentemente desempenha um papel importante no mecanismo da evolução linguística. [...] A diferenciação sexual com que estamos lidando depende claramente de padróes de interação social na vida diária [...] e de uma postura expressiva que é socialmente mais apropriada para um sexo do que para outro. (LABOV, 1972 [2008], p. 348).

Com base nessas considerações, dividimos a variável gênero (sexo) em:

- Masculino;

- Feminino.

b) Faixa etária

A sociolinguística variacionista postula que as mudanças podem ser apreendidas durante a sua implementação através do que se denominou análise em tempo aparente. Levando em consideração ainda a hipótese clássica, segundo a qual "o comportamento linguístico de cada geração reflete um estágio da língua, com os grupos etários mais jovens introduzindo novas alternantes que substituem gradativamente aquelas que caracterizam a fala de indivíduos de faixas etárias mais velhas." (ARAÚJO, 2007, p. 395), neste trabalho, faremos uma comparação da linguagem de pessoas de diferentes faixas etárias. Dessa forma, poderemos verificar se o fenômeno aqui analisado apresenta indícios de mudança em progresso ou de variação estável. As faixas que analisaremos são as mesmas estipuladas pelo Projeto NORPOFOR:

- 15-25 anos;

- 26-49 anos; 
-50 anos em diante.

c) Escolaridade

A variável escolaridade está sempre presente nas pesquisas sociolinguísticas, visto que, geralmente, os falantes com menor nível de escolaridade são os que mais usam as formas não padrão. Normalmente, é na escola onde o indivíduo é mais exposto ao conhecimento sistematizado da língua e às suas formas padrão.

Neste trabalho, estamos levando em consideração apenas falantes pertencentes à norma popular, ou seja, não estamos analisando falantes com nível superior de ensino. Assim, decidimos controlar essa variável (escolaridade), tomando para análise dois níveis de escolaridade apresentados pelo projeto NORPOFOR:

$-0-4$ anos;

$-9-11$ anos.

A faixa intermediária do NORPOFOR, de 5 a 8 anos de estudo, não foi contemplada aqui e a justificativa para isso já foi dada.

d) Registro

Nesta variável, analisaremos o tipo de discurso que envolve cada informante. Neste corpus, temos dois tipos: diálogo entre informante e documentador (DID) e diálogo entre dois informantes (D2). Acredita-se, por um lado, que situações de maior "pressão", como o fato de o informante não se sentir à vontade com o documentador ou mesmo de saber que sua fala está sendo gravada, causam uma maior tensão e controle linguístico por parte do falante. Por outro lado, situaçóes mais "relaxadas", como o relato de uma experiência pessoal, acarretam uma fala menos tensa, conhecida pela sociolinguística como vernáculo - que deve ser a fala a ser analisada principalmente em pesquisas de natureza fonológica.

Em geral, espera-se que o DID apresente um comportamento linguístico, de certa forma, tenso (não relaxado) pelo informante, o que pode ser um reflexo da presença do inquiridor e do gravador, embora a nossa escolha pela audição 
dos quarenta minutos ${ }^{21}$ finais da gravação procure eliminar um pouco desse controle exercido.

O D2, por sua vez, normalmente reflete um discurso mais relaxado. Em geral, eles são realizados entre duas pessoas que já se conhecem e possuem certo grau de intimidade, fato que poderia eliminar boa parte da formalidade na fala delas. Dessa forma, espera-se que haja um maior número de variantes inovadoras nesse estilo de fala. No entanto, esse tipo de discurso possui, algumas vezes, a desvantagem da sobreposição de vozes, o que dificulta a transcrição das ocorrências. Então, tomamos para controle, os fatores:

$-\mathrm{DID}$;

$-\mathrm{D} 2$.

O método variacionista aqui utilizado torna possível identificar e analisar quantitativamente (e, consequentemente, qualitativamente) o efeito de fatores linguísticos e extralinguísticos que condicionam os fenômenos de variação e mudança linguística, em situações reais de comunicação. Não pretendemos aqui calcular apenas as frequências brutas dos resultados, pois, segundo Naro (2004, p. 19), elas "podem ser falaciosas, porque seu cálculo não leva em conta as inter-relações existentes entre as categorias que atuam numa regra variável." Para que possamos definir a força de atuação conjunta das categorias existentes num determinado contexto, utilizaremos métodos computacionais que separam os efeitos individuais.

Neste trabalho, tomaremos como base o sistema logístico proposto por Susan Pintzuk (1988), conhecido como VarbRul (do inglês Variable Rules Analysis). O VarbRul servirá aqui para medir os efeitos das variáveis independentes sobre a variável dependente, objeto de nossa investigação. Com base nesse modelo logístico, a média do grupo de fatores é ponderada pelo número de dados empíricos de que se dispóe para cada fator com o objetivo de evitar que fatores que apresentam poucos dados tenham maior influência no cálculo. (NARO, 2004, p. 23).

Para o ambiente Windows, o pacote VarbRul tem a versão GoldVarb X, utilizada nesta pesquisa. Essa versão foi elaborada por Sankof, Tagliamonte e Smith $(2005)^{22}$, tomando como base a versão GoldVarb 2.0 de Rand \& Sankof (1990) para Macintosh. 
Esse programa irá fornecer o número de ocorrências das variantes analisadas para cada fator, o percentual de aplicação da regra e o peso relativo (P.R.). Sobre este último, Guy e Zilles (2007, p. 211) explicam que "o efeito [...] pode ser neutro $(0,50)$, favorecedor (acima de 0,50 ) ou desfavorecedor (abaixo de 0,50$)$ em relação à aplicação da regra em estudo.”

Com base nos resultados das análises desse programa, podemos confirmar ou não nossas hipóteses iniciais. Dessa forma, se um grupo de fator for apontado como não significativo pelo programa, a hipótese será refutada; se o grupo for apontado como significativo, mas se sua influência não é como se previu no valor de aplicação, a hipótese também é rejeitada; e se o grupo for significativo e se sua influência for como a prevista no valor de aplicação, finalmente, a hipótese será confirmada.

O programa nos possibilita ainda, a fim de visualizarmos melhor a influência que cada fator pode ter sobre outro, realizar interações entre eles (como fizemos na seção 4.1). Além disso, para que possamos encontrar melhores resultados, podemos fazer amálgamas entre os fatores e excluí-los.

Outras informações importantes que o programa nos fornece são o input, significância, o teste de verossimilhança (log likelihood), Sobre o input, é importante observarmos que quanto mais próximo de zero for o seu valor, menor a probabilidade de ocorrência do fenômeno. Por exemplo, em uma das rodadas que analisamos, o input foi de apenas 0,033, significando que a possibilidade de haver aspiração de /v/ é muito pequena no contexto analisado. Encontramos em Scherre (1993, p. 27) uma explicação para a significância: "O programa trabalha com uma margem de erro de 5\% (threshhold, 05), ou seja, se o nível de significância for acima deste valor, previamente arbitrado, os resultados não são considerados estatisticamente significativos." Sobre o teste de verossimilhança, Bisol e Brescancini (2002, p. 35-6) explicam que: "o likehood indica o grau de probabilidade de os dados terem sido gerados pelo modelo. Os valores probabilísticos que resultam no valor mais alto do likelihood são considerados os mais prováveis de terem sido gerados pelo modelo." Além disso, a rodada pode apresentar nocaute. Isso ocorre quando "um fator que, num dado momento da análise, corresponde a uma frequência de 0 ou 100\% para um dos valores da variável dependente." (GUY; ZILLES, 2007, p.158). 


\section{RESULTADOS E ANÁLISE DE DADOS}

Nesta seção, discutiremos os resultados obtidos para a aspiração de /v/ no contexto início de palavra e na posição intervocálica. No primeiro contexto, foram obtidas 5.962 ocorrências de /v/, o equivalente a 54,12\%, e, no segundo, foram registrados 5.055 dados, o que corresponde a $45,88 \%$, totalizando, assim, 11.017 ocorrências. Nos dois contextos, são encontradas 1.379 (12,5\%) ocorrências da aspiração, enquanto a fricativa labiodental ocorre em 9.638 $(87,5 \%)$ dos dados.

Ao analisarmos os dois contextos de /v/, juntos, tanto em início de palavra quanto em posição intervocálica, realizamos três rodadas. Na primeira, encontramos alguns nocautes; na segunda, eliminamos esses nocautes e obtivemos os resultados que comentaremos a seguir; na terceira rodada, fizemos a interação entre as variáveis sociais selecionadas (gênero/sexo, escolaridade e faixa etária). A seguir, detalharemos cada uma dessas rodadas.

A primeira análise realizada apresentou nocaute em dois grupos de fatores. O primeiro foi o contexto fonológico precedente, com a vogal [o] ], registrando apenas ocorrências da manutenção. O segundo grupo foi o contexto fonológico subsequente, com nocautes na semivogal [j] e na vogal [ũ]. A semivogal [j] só apresentou uma ocorrência em todo o corpus, e esta foi da manutenção: "Flá[v] ia”. A vogal [ũ] apresenta apenas duas ocorrências, ambas da manutenção: "criança [v]umitando" (Inq. 94) e "depois [v] um" (Inq. 93). Supõe-se que a não realização da aspiração na palavra "Flávia" esteja relacionada ao fato de que seja um nome próprio.

$\mathrm{Na}$ segunda rodada, foram retirados os fatores que apresentaram nocautes, já que o Goldvarb X não calcula o peso relativo nem faz a seleção dos grupos mais relevantes se os nocautes permanecerem na rodada.

Excluídos os nocautes, passamos a analisar 10.955 dados, dos quais $1.379(12,6 \%)$ são de ocorrências aspiradas, como ilustra o gráfico 1. Nessa rodada, o melhor nível de análise selecionado pelo programa apresentou: input 0,043 , significância 0,000 , ou $\mathrm{p}<10^{-4}$, e log likelihood $\left.{ }^{24}-2780,782\right)$ e foram selecionados os seguintes grupos relevantes para o fenômeno em análise (nesta ordem): contexto fonológico subsequente, tonicidade, classes de palavras, escolaridade, faixa etária, frequência de uso, registro, contexto fonológico precedente e gênero/sexo. Os grupos excluídos foram apenas (nesta ordem): dimensão do vocábulo e tipo de sílaba. 


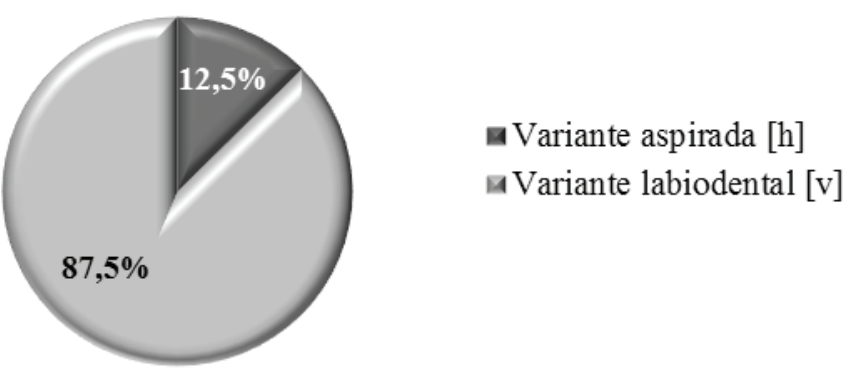

GRÁFICO 1: Distribuição das ocorrências por variante após a retirada dos nocautes

A seguir, detalharemos os resultados de cada variável considerada relevante ao fenômeno da aspiração.

a) Contexto fonológico subsequente

Segundo Katamba (1996), normalmente um fonema tem alofones que são dependentes, numa determinada posição, de outros sons que os circunvizinham. Por isso, como dito anteriormente, é importante levar em conta a noção de direcionalidade. (ver TAB 2)

\section{TABELA 2}

Atuação do contexto fonológico subsequente sobre a aspiração de /v/

\begin{tabular}{|c|c|c|c|c|}
\hline Fatores & Aplica/Total & $\%$ & P.R. & Ilustrações da nossa amostra \\
\hline [0] & $2 / 56$ & 3,6 & 0,846 & boa [h]ontade \\
\hline$[\tilde{\mathrm{e}}]$ & $53 / 419$ & 12,6 & 0,707 & menino [h]ão / le[h] ando \\
\hline [a] & $1064 / 3570$ & 29,8 & 0,702 & num $[\mathrm{h}] \mathrm{ai} / \mathrm{pensa}[\mathrm{h}] \mathrm{a}$ \\
\hline$[\varepsilon]$ & $48 / 860$ & 5,6 & 0,582 & continha [h]éa / ti[h]esse \\
\hline [o] & $61 / 1305$ & 4,7 & 0,487 & eu [h]ô / le[h]ô \\
\hline$[\mathrm{u}]$ & $18 / 373$ & 4,8 & 0,436 & se [h] ucê / no[h]o \\
\hline$[\tilde{\mathrm{e}}]$ & $16 / 484$ & 3,3 & 0,425 & num $[\mathrm{h}] \mathrm{em}$ \\
\hline [0] & $6 / 285$ & 2,1 & 0,410 & pa [h]oltá / ad[h] ogado \\
\hline [i] & $12 / 374$ & 3,2 & 0,342 & num [h]inha \\
\hline [e] & $32 / 1214$ & 2,6 & 0,320 & às [h]eze / ca[h]ei \\
\hline [i] & $67 / 2015$ & 3,3 & 0,247 & ela [h]iu / te[h]e \\
\hline
\end{tabular}

Legenda: Aplica $=$ No de ocorrências apenas da variante aspirada; Total $=$ No de ocorrências da variante aspirada e da variante fricativa labiodental sonora. 
A fim de deixar os nossos resultados mais claros, apresentaremos todos os dados que tiveram até 15 ocorrências em nossa amostra. Assim, a outra (além da que aparece na tabela 2) ocorrência de [o] é também com /v/ em início de palavra: "tenho [h] ontade" (Inq. 19). Todas as ocorrências de [ẽ] são com /v/ em início de palavra, com os verbos "vem" ou "venho", por exemplo: "ela [h] em" e "eu [h] enho". As outras quatro ocorrências de [0] são com /v/ em início de palavra: "e [h] oltava" (Inq. 95 e 132), "num [h] otá" (Inq. 95), "num [h]oto" (Inq. 132), "pa [h] oltá" (Inq. 19). E as 11 ocorrências restantes de [ĩ] também são apenas com /v/ em início de palavra: "gente [h]inha" (Inq. 06), "pa [h]im" (Inq. 06), "e [h]im (Inq. 06 e 49)", "sempe [h] inha” (Inq. 06), "qui [h]inha” (Inq. 46), "em [h] inte (Inq. 111)”, "quando [h]inha” (Inq. 10), "ai [h]im” (Inq. 19), "num [h]im” (Inq. 19), "que [h]im” (Inq. 19).

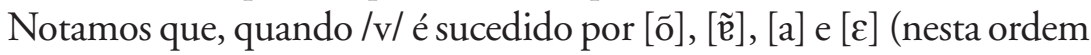
hierárquica), há o favorecimento da variante aspirada, como informam os seus respectivos pesos relativos, 0,846, 0,707, 0,702, 0,582, enquanto as demais vogais, [o], [u], [ẽ], [ ], [i], [e] e [ĩ], inibem o fenômeno, obedecendo a essa ordem decrescente de importância.

Outra observação que fizemos sobre esse fator é que, quando as vogais [ō], [ẽ] e [i)] sucedem /v/, só encontramos ocorrências aspiradas em contexto de início de palavra.

A pesquisa de Roncarati e Uchoa (1988, p.41) e o estudo de Marques (2001) apresentaram resultados semelhantes ao nosso. A primeira analisa o fator "qualidade vocálica", com o intuito de "verificar a hipótese de que determinadas vogais-base favoreceriam o enfraquecimento e o apagamento dos segmentos avizinhados." Esse fator obteve resultado um pouco semelhante ao nosso, pois, na pesquisa desses autores, a vogal mais frequente foi /a/, tanto antecedendo quanto sucedendo $/ \mathrm{v} /$. Ao suceder /a/ obtiveram 0,64 (72/405 - 17\%). Em posição intervocálica, foi o grupo /ava/ o que apresentou os índices mais altos de enfraquecimento $(0,85)$.

O estudo de Marques $(2001)^{25}$ também revela que a vogal /a/ é a principal favorecedora do enfraquecimento de /v/ $(0,76)$. Em segundo lugar, apareceram as vogais nasais $(0,60)$, confirmadas nesta pesquisa pelas vogais [õ] e [e $)]$; em terceiro, surgiram as médias $(0,52)$, cujo índice de probabilidade se deveu, em grande parte, às vogais $[e] \mathrm{e}[\varepsilon]$, aqui confirmadas apenas por $[\varepsilon]$. Por último e inibindo a variante aspirada, temos as vogais altas $(0,34)$, as quais também se mostraram inibidoras nos nossos resultados. 
b) Tonicidade

A variável tonicidade nos mostrou que apenas as pós-tônicas $(0,738)$ agem no sentido de favorecer a variante aspirada, enquanto as pré-tônicas $(0,241)$ e as tônicas $(0,476)$ o inibem (ver tabela 3$)$.

TABELA 3

Atuação da tonicidade sobre a aspiração de /v/

\begin{tabular}{ccccc}
\hline Fatores & $\begin{array}{c}\text { Aplical } \\
\text { Total }\end{array}$ & $\%$ & P.R. & Ilustraçóes da nossa amostra \\
\hline Pós-tônicas & $922 / 3065$ & 30,1 & 0,738 & deixa[h]a \\
Tônicas & $428 / 5611$ & 7,6 & 0,476 & pra $[\mathrm{h}] \mathrm{i} / \mathrm{no}[\mathrm{h}] \mathrm{ela}$ \\
Pré-tônicas & $29 / 2279$ & 1,3 & 0,241 & de $[\mathrm{h}]$ agabundo \\
\hline
\end{tabular}

O predomínio da ocorrência da variante aspirada na sílaba pós-tônica deve-se ao grande número de ocorrências das formas no pretérito imperfeito com o grupo /ava/.

Já na pesquisa de Canovas (1991), a única que usa como critério a própria tonicidade da sílaba na qual ocorreriam as fricativas em estudo ${ }^{26}$, houve resultados diferentes dos nossos: as ocorrências aspiradas de /v/ em início de sílaba são bem mais frequentes em sílabas átonas [-ac] $(56 / 970=5,77 \%)$ do que em sílabas tônicas [+ac] $(2 / 774=0,25 \%)$.

c) Classes de palavras

De acordo com Dubois et al. (1973), a produtividade de uma variação é também influenciada pelos níveis morfológicos, pois existem fenômenos que atingem apenas determinadas classes de palavras, não agindo em outras.

Em nossos dados, quanto às classes de palavras, verificamos que o maior aliado da variante aspirada surgiu no grupo que não poderia conter nem verbos nem nomes, nas interjeições $(0,957)$, e todas as ocorrências aspiradas que nele encontramos correspondem à locução interjetiva "Ave Maria!". Assim, verificamos que essa expressão, com base nos dados que encontramos, é praticamente uma regra categórica em relação ao uso da forma aspirada. Os verbos também se mostraram favorecedores do fenômeno $(0,608)$, mas o grupo 
dos nomes apresentou um peso relativo baixíssimo $(0,329)$, inibindo a regra (ver tabela 4).

TABELA 4

Atuação das classes de palavras sobre a aspiração de /v/

\begin{tabular}{ccccc}
\hline Fatores & Aplica/Total & $\%$ & P.R. & Ilustraçôes da nossa amostra \\
\hline Outros & $24 / 54$ & 44,4 & 0,957 & A[h]e Maia \\
Verbos & $1267 / 6596$ & 19,2 & 0,608 & inda [h]ai / puxa[h]a \\
Nomes & $88 / 4305$ & 2,0 & 0,329 & continha[h]éa / dú[h]ida \\
\hline
\end{tabular}

Em Roncarati e Uchoa (1988), essa variável também se destaca e, no estudo de Marques (2001), também é considerada relevante.

d) Escolaridade

Diversas pesquisas têm demonstrado uma relação próxima entre o nível de escolaridade do falante e sua escolha por determinados tipos de variantes. Labov, em 1966, ao estudar o inglês falado em Nova Iorque, observou que os falantes com menor escolaridade usavam com maior frequência as formas não padrão, enquanto as formas padrão eram mais utilizadas pelos mais escolarizados. Essa constatação vem sendo uma tendência de muitos trabalhos na área da sociolinguística quantitativa.

Sobre a relação da escola com a mudança linguística, Marques (2001, p. 75) ressalta que "a escola exerce um importante papel, seja para frear e/ou retardar o fluxo natural de uma mudança, seja para constituir-se um agente fundamental dela”.

Para Oliveira e Silva (2004), a escola, ao basear o ensino da oralidade em uma imitação da língua escrita, determina um certo desempenho linguístico para o falante. $\mathrm{O}$ acesso à norma padrão que a escola possibilita representa, também, um papel social muito importante, já que esse acesso pode ser visto como um instrumento de ascensão social.

Nesta pesquisa, verificamos que o fenômeno dá mostras de que é estigmatizado, pois são os informantes com menor escolaridade (de 0 a 4 anos) os que favorecem a aspiração $(0,629)$. Os que possuem de 9 a 11 anos de escolarização inibiram o seu emprego $(0,380)$ (ver tabela 5$)$. 
TABELA 5

Atuação da escolaridade sobre a aspiração de /v/

\begin{tabular}{cccc}
\hline Fatores & Aplica/Total & $\%$ & P.R. \\
\hline 0 a 4 anos & $955 / 5291$ & 18,0 & 0,629 \\
9 a 11 anos & $424 / 5726$ & 7,4 & 0,380 \\
\hline
\end{tabular}

No trabalho de Roncarati e Uchoa (1988), o fator escolaridade, quando se refere apenas a $/ \mathrm{v} /$, revelou resultados diferentes, pois os índices de aspiração $(0,89)$ "são menores em falantes com as séries iniciais do $1^{\circ}$ grau"27 (p. 20). Em contrapartida, os resultados do teste de atitudes, aplicado pelos autores, revelaram resultados mais voltados para determinados itens lexicais: "As formas menos favoravelmente cotadas, [...] 'tele[h] isão' ${ }^{28}$, seriam produzidas por aqueles falantes do grupo 'c': menor escolaridade, menor status e não-urbanos" (RONCARATI; UCHOA, 1988, p. 93).

Os resultados de Canovas (1991), em relação à escolaridade, também foram diferentes dos nossos, pois são os falantes de $3^{\circ}$ grau completo os que mais favorecem a regra, com $5,73 \%$ das ocorrências (34/593). Em seguida, vêm os falantes que possuíam até o $1^{\circ}$ grau $(3,60 \%$ ou $21 / 583)$ e, por último, os que tinham o $2^{\circ}$ grau completo $(0,52 \%$ ou $3 / 568)$. Pelicioli (2008), aproximadamente dezessete anos depois, obteve os mesmos resultados: os falantes de nível universitário foram responsáveis por 52,1\% (25/48) das realizações aspiradas de $/ \mathrm{v} /$, enquanto os de nível fundamental ficaram com apenas $47,9 \%$ (23/48) das ocorrências. Por isso, pode-se dizer que, em Salvador, a variante aspirada não é estigmatizada.

Já no estudo de Marques (2001) ${ }^{29}$, os informantes analfabetos foram os maiores aliados da variante aspirada $(0,59)$, obtendo um índice muito próximo aos que tinham de 1 a 4 anos de escolarização $(0,58)$. Os indivíduos com 5 a 8 anos de escolaridade também agiram positivamente sobre o fenômeno $(0,56)$, porém os falantes com 9 a $11(0,34)$ e mais de 11 anos $(0,29)$ inibiram a regra. Dessa forma, percebemos que a forma aspirada também é estigmatizada em João Pessoa.

e) Faixa etária

Estudos feitos por Labov, em Nova Iorque, no ano de 1966, e em Martha's Vineyard, no ano de 1963, comprovaram que os mais jovens tendem a usar as 
formas mais inovadoras, enquanto os mais idosos tendem a empregar mais as formas conservadoras (padrão). O fator faixa etária indica o estado em que se encontra uma variável numa comunidade e o comportamento que ela pode orientar, se o fenômeno se encontra em variação estável ou em processo de mudança (MARQUES, 2001).

Em nossos dados, a faixa etária foi a variável selecionada em quinto lugar e, por meio dela, constatamos que os mais idosos (de 50 anos ou mais) são os únicos que favorecem a aspiração $(0,614)$, ao passo que os mais jovens (de 15 a 25 anos) e os adultos (26 a 49 anos) inibem a regra: 0,391 e 0,484, respectivamente (ver tabela 6 ). Também notamos que, à medida que cresce a faixa etária do informante, aumenta a proporção de uso da variante aspirada.

TABELA 6

Atuação da faixa etária sobre a aspiração de /v/

\begin{tabular}{llll}
\hline Fatores & Aplica/Total & $\%$ & P.R. \\
\hline 50 anos ou mais & $684 / 3854$ & 17,7 & 0,614 \\
26-49 anos & $405 / 3631$ & 11,2 & 0,484 \\
$15-25$ anos & $290 / 3532$ & 8,2 & 0,391 \\
\hline
\end{tabular}

Em Roncarati e Uchoa (1988), encontramos um resultado diferente, pois são os jovens ${ }^{30}$ que mais frequentemente usam a variante aspirada $(0,80)$. Dessa forma, ao compararmos os resultados dessa variável na pesquisa de Roncarati e Uchoa (1988) com os obtidos neste estudo (GRAF. 2), cujos dados foram coletados cerca de quinze anos depois ${ }^{31}$, podemos inferir que há uma tendência ao desaparecimento das formas aspiradas no falar fortalezense, visto que elas aumentavam à medida que crescia a faixa etária do falante: criança $(0,20)$, adolescentes $(0,30)$, jovens $(0,79)$ e adultos $(0,70)$.

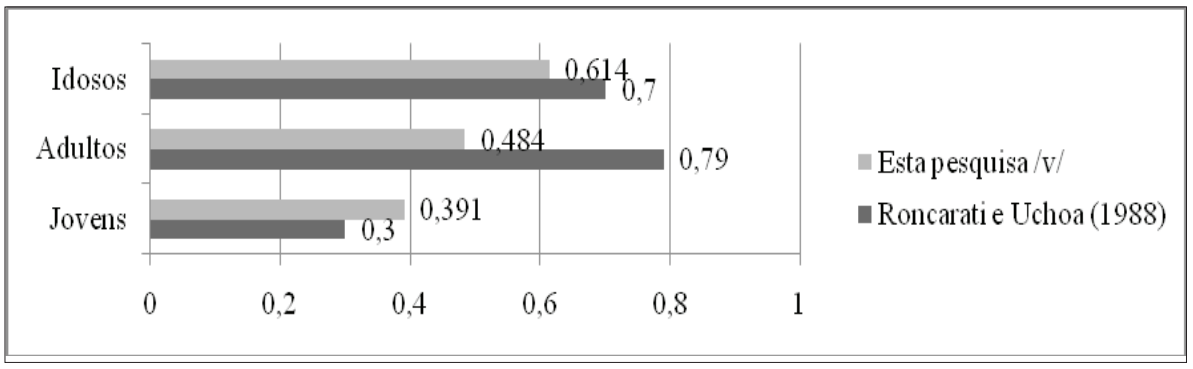

GRÁFICO 2: Pesos relativos da faixa etária sobre a aspiração de /v/ no estudo de Roncarati e Uchoa (1988) e nesta pesquisa 
Na pesquisa de Canovas (1991), os resultados também dizem isso sobre o falar de Salvador: os mais idosos são os que mais realizam a variante aspirada (4,05\%, 25/617), seguidos dos de 21 a 45 anos (3,42\%, 21/613) e dos de 13 a 20 anos $(2,33 \%, 12 / 514)$. O estudo de Pelicioli (2008) também constatou que os mais idosos (de 46 a 61 anos), entre os soteropolitanos, são os que mais aspiram /v/ (58,3\%, 28/48), diferentemente dos de 20 a 30 anos (41,7\%, 20/48) que aplicam menos a regra.

Já em João Pessoa, houve um resultado diferente: a pesquisa de Marques (2001) verificou que são os indivíduos da faixa etária de 26 a 49 anos os que mais favoreceram a aspiração $(0,58)$, enquanto as outras faixas etárias inibiram a aplicação do fenômeno (0,43 para os de 15 a 25 anos e 0,47 para os de 50 anos ou mais). (GRAF. 3).

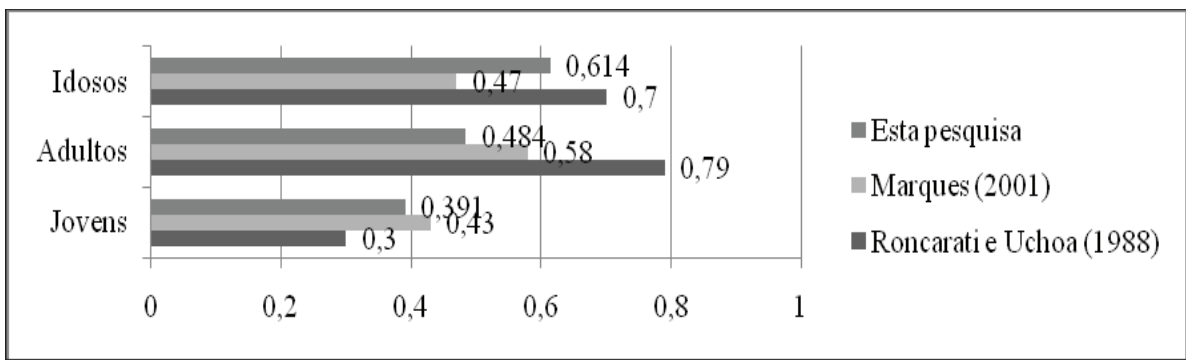

GRÁFICO 3: Pesos relativos da faixa etária sobre a aspiração de /v/ no estudo de Marques (2001), no de Roncarati e Uchoa (1988) e nesta pesquisa

f) Frequência de uso

A variável frequência de uso apresentou resultados que comprovaram nossas hipóteses, pois, quanto maior a frequência de uso de uma palavra, maior foi a sua probabilidade de aspiração.

Por esses resultados, podemos verificar ainda que apenas os termos pouco frequentes $(0,398)$ e os termos pouquíssimo frequentes $(0,346)$ inibem a regra; nos demais fatores desta variável há o favorecimento da variante aspirada (ver tabela 7). 
TABELA 7

Atuação da frequência de uso sobre a aspiração de /v/

\begin{tabular}{ccccc}
\hline Fatores & $\begin{array}{c}\text { Aplica/ } \\
\text { Total }\end{array}$ & $\%$ & P.R. & $\begin{array}{c}\text { Ilustraçóes da nossa } \\
\text { amostra }\end{array}$ \\
\hline Termo extremamente frequente & $512 / 2691$ & 19,0 & 0,612 & inda $[\mathrm{h}] \mathrm{ai} / \mathrm{ta}[\mathrm{h}] \mathrm{a}$ \\
Termo muito frequente & $203 / 2178$ & 9,3 & 0,597 & mai $[\mathrm{h}] \mathrm{elho} / \mathrm{fica}[\mathrm{h}] \mathrm{a}$ \\
Termo frequente & $283 / 2104$ & 13,5 & 0,512 & num $[\mathrm{h}] \mathrm{inh} / \mathrm{da}[\mathrm{h}] \mathrm{a}$ \\
Termo pouco frequente & $167 / 1626$ & 10,3 & 0,398 & num $[\mathrm{h}] \mathrm{ia} / \mathrm{si}[\mathrm{h}] \mathrm{iu}$ \\
Termo pouquíssimo frequente & $212 / 2418$ & 8,8 & 0,346 & $\begin{array}{c}\text { uma }[\mathrm{h}] \mathrm{acaria} / \\
\text { cutulh]elo }\end{array}$ \\
\hline
\end{tabular}

Ao fazermos a contagem de cada palavra ocorrida na nossa amostra, verificamos que nos três primeiros lugares estão: em contexto de início de palavra - "/v/ai", "/v/ocê(is) - /v/ucê(is)", "/v/o - /v/ou"; em contexto intervocálico "ta/v/a(m) - esta/v/a(m)", "ti/v/e - ti/v/é - ti/v/esse - ti/v/eram - ti/v/éssemos - ti/v/erem", "con/v/ersa - con/v/ersando - con/v/erso - con/v/ersava - con/v/ ersou - con/v/ersei - con/v/ersarem - con/v/erse".

Assim, verificamos que, apesar de terem utilizado critérios diferentes dos nossos para categorizar esta variável, as formas citadas por Roncarati e Uchoa (1988) são semelhantes às nossas, confirmando, portanto, que quanto maior a frequência de uso de um item maior será a sua probabilidade de ser aspirado.

Por último, após realizar o levantamento lexical, Roncarati e Uchoa (1988) mostram apenas a hierarquia dos fatores selecionados pelo programa para a variante aspirada. Considerando-se os contextos de início de palavra e intervocálico (juntos), essa ordem foi: segmento aspirado nas formas em /ava/, vogal seguinte /a/, distância 3 a 5 da tonicidade seguinte, falantes jovens, falantes com $1^{\mathrm{a}}$ a $4^{\mathrm{a}}$ séries do $1^{\mathrm{o}}$ grau, falantes da classe média, segmento aspirado no interior da palavra, distância 1 da tonicidade antecedente e falantes de sexo masculino e feminino.

A outra pesquisa que testa essa variável (frequência de uso do item lexical) é a de Pelicioli (2008), a qual encontra, em seus dados de aspiração, apenas: o sufixo do imperfeito /ava/, as flexões do verbo "ir" e a única ocorrência do advérbio "inclusive". No entanto, por não ter submetido os dados de /v/ ao programa, não nos traz nenhuma ordem de fatores selecionados após relatar os itens lexicais mais recorrentes em sua pesquisa. 
g) Registro

A sétima variável selecionada nesta rodada foi o registro. Pelos resultados que encontramos, ela não confirmou a hipótese de que nos Diálogos entre Informante e Documentador (DID) obteríamos menos dados aspirados, pois neles o peso relativo foi maior $(0,551)$ do que nos Diálogos entre dois Informantes (D2) $(0,404)$ (ver tabela 8$)$.

TABELA 8

Atuação do tipo de registro sobre a aspiração de /v/

\begin{tabular}{cccc}
\hline Fatores & Aplica/Total & $\%$ & P.R. \\
\hline DID & $1014 / 7173$ & 14,1 & 0,551 \\
D2 & $365 / 3844$ & 9,5 & 0,404 \\
\hline
\end{tabular}

Embora nos DID a aspiração tenha sido maior, percebemos que isso acontece discretamente, aproximando-se do ponto neutro. Por isso, constatamos que o fenômeno ocorre independentemente do contexto de fala, o que poderia caracterizar uma marca regional, típica do falar fortalezense, visto que os informantes não se inibem durante a entrevista. Outra explicação para isso é que, durante a fase das transcrições, notamos que os entrevistadores dos DID tinham conseguido criar um ambiente de muita informalidade, cumprindo seu objetivo inicial, como relata Araújo (2007). Em contrapartida, observamos também que, nos D2 analisados, os informantes não se mostraram muito à vontade.

Os demais trabalhos que analisaram a regra não fizeram o controle desta variável e, por isso, não podemos estabelecer nenhum paralelo entre os resultados deles e os nossos. Apesar disso, verificamos que eles afirmam que "a situação de fala informal, rápida, relaxada e menos monitorada parece favorecer o enfraquecimento." (RONCARATI; UCHOA, 1988, p. 93) e que "os estilos formal/informal, tenso/distenso, monitorado/não-monitorado." (ARAGÃO, 2009, p. 199) estão entre os fatores que mais marcaram a neutralização dos fonemas /v, z, 3, r $\mathrm{r}^{32}$ /, situação também corroborada por Alencar (2007, p. 120): "em termos discursivo-pragmáticos, em situação menos monitorada, digamos mesmo, relaxada, mais rápida, a fala favorece a neutralização [...]”. 
h) Contexto fonológico precedente

Em nossos dados, a variável contexto fonológico precedente apresentou, mais uma vez, as vogais [a] $(0,932)$ e $[\tilde{a}](0,618)$ como as maiores aliadas da variante aspirada (ver tabela 9). A primeira, novamente, podemos explicar pelo número de dados encontrados com as palavras que contêm o grupo /ava/ (1.816); a segunda explicamos apenas pelas três ocorrências que encontramos, sendo uma delas aspirada, o que fez com que sua probabilidade aumentasse consideravelmente. Os demais contextos favorecedores do fenômeno são, nesta ordem hierárquica: a vogal [ũ] $(0,573)$, a semivogal [j] $(0,534)$, a pausa $(0,523)$ e a vogal $[u](0,520)$. Em contrapartida, a variante aspirada, quando antecedida por consoante, pelas vogais [e], [i], [0], [i] , [ع] e [o] e pela semivogal [w], foi inibida.

TABELA 9

Atuação do contexto fonológico precedente sobre a aspiração de /v/

\begin{tabular}{|c|c|c|c|c|}
\hline Fatores & Aplica/Total & $\%$ & P.R. & Ilustrações da nossa amostra \\
\hline$[\tilde{\mathrm{P}}]$ & $1 / 3$ & 33,3 & 0,932 & amanhã [h]ai \\
\hline [a] & $964 / 3628$ & 26,6 & 0,618 & minina $[\mathrm{h}]$ éa / chama $[\mathrm{h}] \mathrm{a}$ \\
\hline [ũ] & $49 / 468$ & 10,5 & 0,573 & num [h]ão / cun[h]esa \\
\hline [y] & $26 / 380$ & 6,8 & 0,534 & rai $[\mathrm{h}] \mathrm{a} /$ rapai $[\mathrm{h}]$ êi \\
\hline pausa & $32 / 389$ & 8,2 & 0,523 & \# [h] ocê \\
\hline$[\mathrm{u}]$ & $33 / 554$ & 6,0 & 0,520 & quato [h] eiz / chu[h]a \\
\hline [consoante] & $18 / 605$ & 3,0 & 0,486 & às $[\mathrm{h}]$ eze \\
\hline [e] & $38 / 516$ & 7,4 & 0,451 & cê [h]ai / ne[h]oso \\
\hline [w] & $47 / 828$ & 5,7 & 0,442 & eu vô / Sil[h]a \\
\hline [i] & $108 / 2106$ & 5,1 & 0,415 & gente $[\mathrm{h}] \mathrm{amo} / \mathrm{ti}[\mathrm{h}] \mathrm{e}$ \\
\hline [0] & $15 / 397$ & 3,8 & 0,382 & só $[\mathrm{h}] \mathrm{ai} / \mathrm{no}[\mathrm{h}] \mathrm{a}$ \\
\hline$[\tilde{1}]$ & $3 / 130$ & 2,3 & 0,352 & em [h] inte / in [h] erno \\
\hline$[\varepsilon]$ & $37 / 562$ & 6,6 & 0,349 & le[h]á \\
\hline [o] & $8 / 389$ & 2,1 & 0,292 & jogadô [h]ô / po[h]o \\
\hline
\end{tabular}

Outra observação que fizemos sobre esse fator é que, quando /v/ é precedido por [e)], pausa e consoante, só encontramos ocorrências aspiradas em contexto de início de palavra. Já quando é precedido por $[\varepsilon]$, suas ocorrências são apenas intervocálicas.

Entre os dados com até 15 ocorrências, encontramos as outras duas ocorrências de $[\mathfrak{e})]$ (da manutenção), também com /v/ em início de palavra: 
"manhã [v]amo" (Inq. 50) e "manha [v] ocê" (Inq. 132). Para pausa e consoante, enquanto contextos precedentes, as outras ocorrências são também com $/ \mathrm{v} / \mathrm{em}$ início de palavra. As outras 13 ocorrências de [0] são: "no[h]ela" (Inq. 46 e 46), "no[h] a" (Inq. 129, 19 e 19), "po[h]a" (Inq. 59), "só [h]ai " (Inq. 153, 09, 09, 49, 49 e 143) e "só [h] ô" (Inq. 18). A outra ocorrência de [ĩ] é: "assim [h]amo" (Inq. 153). As outras ocorrências de $[\varepsilon]$ são também com /v/ intervocálico. E as seis ocorrências restantes de [o] são: "no[h]o" (Inq. 95, 95, 09, 19), "po[h] o" (Inq. 93) e "vô [h] ai" (Inq. 46).

Em outras pesquisas, essa variável também foi considerada relevante, a exemplo dos trabalhos de Roncarati e Uchoa (1988) e de Marques (2001).

\section{i) Gênero/sexo}

As diferenças linguísticas devidas ao sexo, segundo Chambers e Trudgill (1980 [1998]), ocorrem desde a fala das crianças. Para isso, citam como exemplo a pronúncia do /r/ pós-vocálico em Edimburgo, onde há um padrão de diferenciação, mesmo na fala de crianças de seis anos de idade.

Para Monteiro (2000, p. 76), a diferença sexual é, antes de tudo, "um fato de ordem sociocultural que se reflete na língua enquanto sistema semiótico entre outros." Estudos sociolinguísticos que envolvem a variável sexo normalmente revelam que as mulheres costumam utilizar as formas prestigiadas socialmente (padrão), enquanto os homens favorecem mais as formas menos valorizadas (não padrão).

Segundo Paiva (2004, p. 36), as mulheres também tendem a "liderar processos de mudança linguística, estando, muitas vezes, uma geração à frente dos homens." No estudo de Labov ([1972] 2008), sobre a pronúncia de $[\mathrm{r}]$ pós-vocálico no inglês de Nova York, podemos comprovar isso, pois a pronúncia retroflexa, forma inovadora, mas de prestígio, predominou entre as mulheres. No entanto, quando a forma é socialmente desprestigiada, os homens é que lideram o processo de mudança, e as mulheres assumem uma atitude conservadora. Assim, "o que se pode generalizar, pelo momento, é a maior sensibilidade feminina ao prestígio social atribuído pela comunidade às variantes linguísticas." (PAIVA, 2004, p. 37).

Essa maior sensibilidade pode ser explicada também pelo maior formalismo associado aos papéis femininos e pelo fato de a posição social delas 
estar menos assegurada do que a do homem. Em virtude disso, as mulheres sentem a necessidade de resguardar a face e de manifestar um comportamento que não ameace sua aceitação social.

Em nossos dados, a última variável selecionada pelo programa foi o gênero/sexo, o que significa que é a menos relevante para a variante aspirada. Os resultados obtidos para este grupo corroboram com as demais pesquisas sociolinguísticas que selecionam esta variável, pois são os homens os que favorecem a variante estigmatizada $(0,538)$, enquanto as mulheres inibem a regra $(0,464)$ (ver tabela 10$)$. Esses números, porém, devem ser vistos com cautela, porque, apesar de os homens serem favorecedores do fenômeno, o peso relativo que lhes é atribuído está muito próximo do ponto neutro, assim como as mulheres também apresentam um peso que se aproxima de 0,50 . Isso nos leva a acreditar que os dois gêneros/sexos não destoam muito no emprego da variante aspirada.

TABELA 10

Atuação do gênero/sexo sobre a aspiração de /v/

\begin{tabular}{cccc}
\hline Fatores & Aplica/Total & $\%$ & P.R. \\
\hline Homens & $601 / 5343$ & 11,2 & 0,538 \\
Mulheres & $778 / 5612$ & 13,8 & 0,464 \\
\hline
\end{tabular}

Em Roncarati e Uchoa (1988), o fator sexo não foi considerado estatisticamente relevante, mas eles relatam que os homens tendem a aspirar mais ligeiramente do que as mulheres. Durante a aplicação do teste de atitudes, na avaliação dos juízes, os falantes do sexo masculino produziriam mais itens aspirados do que as mulheres. Para esse fato, foi levantada a seguinte questão: "[ele] poderia ser interpretado como uma manifestação de 'macho' ao mostrarem relaxamento, displicência, sentir-se à vontade?” (RONCARATI; UCHOA, 1988, p. 93)

Se esse questionamento/hipótese fosse comprovado/a, ele/a poderia ser explicado/a pela suposição de Trudgill (1974, apud PAIVA, 2004), segundo a qual os homens atribuiriam um prestígio encoberto às formas linguísticas:

Se um indivíduo deseja integrar um grupo, deve partilhar, além de suas atitudes e valores, a linguagem característica desse grupo. Nesse caso, determinadas formas de linguagem se investem de um status 
particular, embora sejam desprovidas de prestígio na comunidade linguística em geral. De certa forma, pode-se dizer que os homens estão mais sujeitos à influência do prestígio encoberto das formas linguísticas do que as mulheres, dado que eles possuem mais mobilidade social e maior oportunidade de participação em grupos sociais fechados. (TRUDGILL, 1974, apud PAIVA, 2004, p. 40).

Contrariando os nossos resultados, em João Pessoa, foram as mulheres as que mais favoreceram a aspiração, enquanto os homens mostraram-se inibidores. Marques (2001, p. 84) assim explica o comportamento feminino na comunidade pessoense: "[ele] é latente, ou seja, em certo momento, não se manifesta, mas é capaz de se revelar ou desenvolver quando as circunstâncias são favoráveis."

\subsection{Interação entre as variáveis sociais selecionadas}

Embora não ocupando as primeiras posições, o gênero/sexo, a escolaridade e a faixa etária foram considerados relevantes pelo programa. Como esta é uma pesquisa sociolinguística, é fundamental aprofundarmos o entendimento da atuação desses fatores. Por isso, realizamos mais uma rodada, apresentando as três interações.

Para esta rodada, o melhor nível de análise escolhido pelo programa foi o step up 64 (input 0,040, significância 0,008 e log likelihood-2731,381), cujas variáveis selecionadas foram (nesta ordem): contexto fonológico subsequente, tonicidade, interação entre faixa etária e escolaridade, classes de palavras, interação entre faixa etária e gênero/sexo, frequência de uso, registro, contexto fonológico precedente e interação entre escolaridade e gênero/sexo. Com relação às variáveis linguísticas selecionadas, observamos que os resultados não divergem dos da rodada anterior, apenas os fatores apresentam pequenas alterações nos seus valores. A seguir, apresentaremos as observações feitas para as interações selecionadas.

a) Faixa etária x escolaridade

Os dados da interação entre faixa etária e escolaridade mostram que há uma diminuição no favorecimento da variante aspirada pelos idosos (de 
0,619 passam para 0,577 ) e jovens (de 0,447 passam para 0,362 ), quando eles adquirem mais escolaridade; a faixa de 26 a 49 anos, no entanto, atua de forma quase neutra, independentemente do grau de escolaridade (ver gráfico 4). Observamos também que os mais idosos apresentam uma diminuição apenas discreta da forma aspirada, mas continuam favorecendo o seu uso. O contrário acontece com os mais jovens que, em nenhum nível de escolaridade, favorecem a regra. Dessa forma, esses dados nos levariam a afirmar que, de fato, há indícios de uma mudança em progresso, visto que os jovens não favorecem a variante aspirada, e o acesso ao ensino formal parece ser responsável por isso uma vez que os idosos com mais escolaridade tendem a favorecer menos o fenômeno.

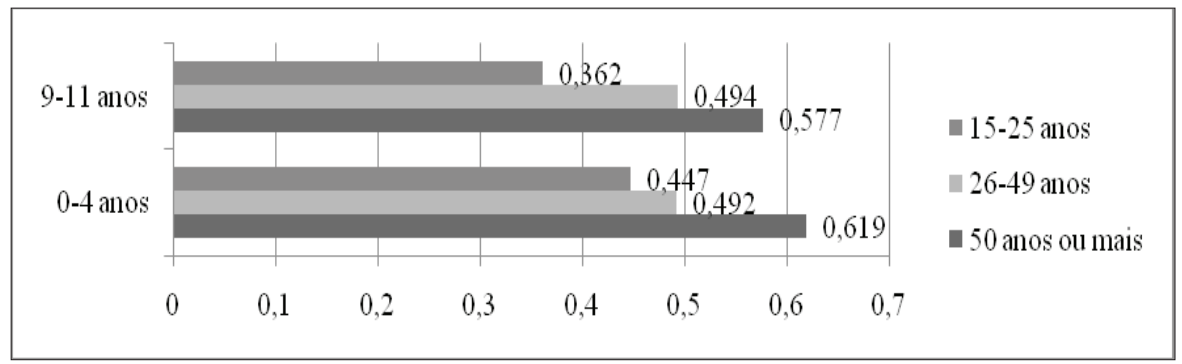

GRÁFICO 4: Pesos relativos da interação entre a faixa etária e a escolaridade sobre a aspiração de /v/

Em Marques (2001), onde encontramos resultados diferentes, são os idosos que permanecem quase estáveis até os oito primeiros anos de escolarização ${ }^{33}$, realizando a aspiração de maneira equilibrada. No entanto, a partir dos nove anos de escolarização, esse uso diminui drasticamente (aproximadamente 0,19 ). Os informantes de 15 a 25 anos também apresentam resultados diferentes dos nossos, pois favorecem a aspiração até os quatro primeiros anos de escolarização - 0,58 (0 ano), 0,70 (de 1 a 4 anos) - e, após isso, começam a inibi-lo - 0,45 (de 5 a 8 anos) e 0,25 (de 9 a 11 anos). Os adultos (de 26 a 49 anos) apresentam resultados bem diferentes dos nossos, pois, enquanto analfabetos, eles favorecem o fenômeno (aproximadamente, 0,60 ) e, durante os quatro primeiros anos de escolarização, passam a inibir esse uso (aproximadamente, 0,40). Já com 5 a 8 anos de escolaridade, eles voltam a utilizar preferencialmente a variante aspirada 
(aproximadamente, 0,71) e, com 9 a 11 anos, esse uso cai, mas continua um pouco favorável (aproximadamente, 0,57).

A interação desses grupos de fatores, feita por Pelicioli (2008), também mostra resultados diferentes. Em uma pequena amostra com um total de 48 ocorrências aspiradas, os falantes de 46 a 61 anos, de nível universitário, favorecem mais a variante aspirada $(43,7 \%-21 / 48)$, enquanto os de nível fundamental ficam com apenas $14,6 \%$ (7/48) das ocorrências. Já com os mais jovens, de 20 a 30 anos, o fenômeno se inverte e apresenta resultados semelhantes aos de Marques (2001): quando possuem o nível fundamental, eles detêm 33,3\% (16/48) dos dados, enquanto, no nível superior, esse índice cai para $8,3 \%(4 / 48)$.

b) Faixa etária x gênero/sexo

Percebemos resultados um pouco diferentes dos que obtivemos quando as variáveis agiam sem essa interação, pois as mulheres, quando estão entre os 26 e 49 anos de idade, são aliadas da aspiração (0,580). No entanto, apenas nessa faixa etária, elas atuam no sentido de favorecer o fenômeno; nas demais faixas, são inibidoras da regra (0,465 - jovens, 0,456 - idosas) (ver gráfico 5). Já os homens, somente quando idosos $(0,613)$, favorecem a variante aspirada; quando jovens, comportam-se de forma neutra $(0,509)$ e, quando adultos, inibem o fenômeno $(0,374)$.

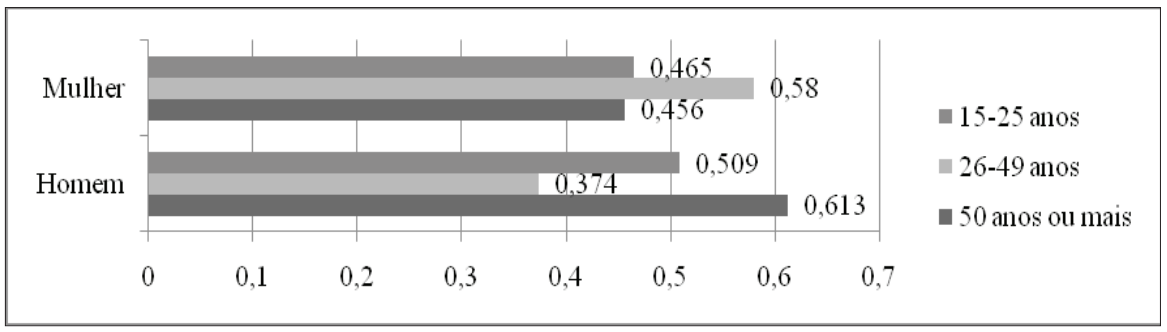

GRÁFICO 5: Pesos relativos da interação entre a faixa etária e o gênero/sexo sobre a aspiração de /v/

Kemp (1979 apud CARVALHO, 2000) afirma que homens e mulheres falam diferenciadamente, de acordo com a faixa etária em que estejam. Ela ressalta que a interação entre essas duas variáveis pode revelar inúmeras diferenças linguísticas entre homens e mulheres, as quais costumam ser mais encontradas 
nas faixas mais avançadas, enquanto, nas faixas mais jovens, essas diferenças são menos explícitas. Essa ideia é corroborada por Paiva (2004). Para essa autora,

a aproximação do comportamento linguístico de falantes mais jovens pode ser um reflexo de que, nessa faixa etária, reconfigura-se a atuação do homem e da mulher na sociedade, com diluição das fronteiras entre papéis femininos e masculinos. (PAIVA, 2004, p. 41).

Ao fazer essa mesma interação, Marques (2001) verifica o contrário do que os resultados da variável sexo trouxeram ao serem expostos separadamente: são os homens que produzem a variante aspirada em todas as faixas etárias, principalmente na de 26 a 49 anos; as mulheres só favorecem a variante aspirada quando estão na faixa etária de 15 a 25 anos, e com uma diferença discreta em relação aos homens.

Considerando o papel das mulheres na mudança linguística, segundo Labov (2001), o que observamos na comunidade de fala fortalezense é que, na pesquisa de Roncarati e Uchoa (1988), as mulheres atuaram de forma negativa sobre o fenômeno (embora a diferença entre elas e os homens fosse apenas discreta), enquanto os jovens (de 21 a 24 anos) foram os que mais produziram a variante aspirada. Em nossos dados, observamos que os jovens (de 15 a 25 anos) passaram a atuar de forma negativa, e as mulheres continuaram atuando da mesma forma sobre o fenômeno. Esses resultados podem significar que as mulheres, ao exercerem uma influência negativa sobre a variante inovadora, transmitiram isso para as crianças, as quais poderiam ser, na pesquisa atual, os jovens de 15 a 25 anos.

c) Escolaridade x gênero/sexo

A interação entre escolaridade e gênero/sexo também revela resultados diferentes para o gênero daqueles encontrados quando essa variável foi analisada separadamente. A leitura dos dados dessa interação indica que as mulheres são favorecedoras da aspiração (também) quando possuem de 0 a 4 anos de escolaridade $(0,567)$, mas, no nível de 9 a 11 anos, elas atuam negativamente sobre o fenômeno $(0,403)$. Com isso, identificamos que as mulheres que favorecem a variante aspirada são apenas as adultas (de 26 a 49 anos) e com baixa escolaridade (de 0 a 4 ). Os homens também apresentam uma probabilidade 
maior $(0,668)$ quando possuem o primeiro nível de escolaridade; ao passarem para o segundo, inibem a variante aspirada $(0,378)$ (ver gráfico 6$)$.

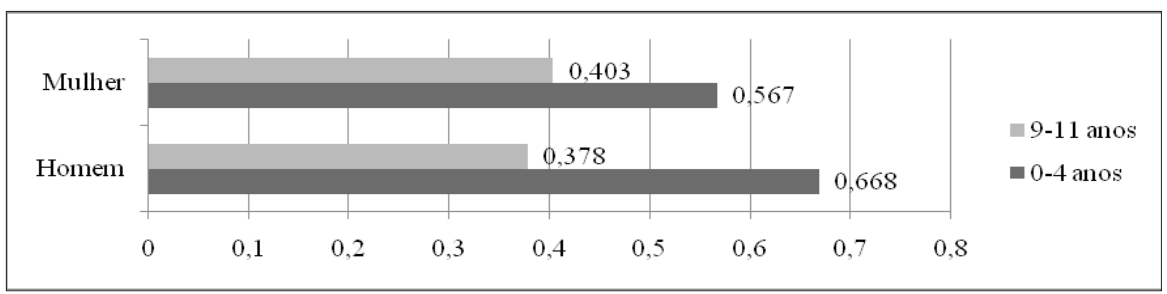

GRÁFICO 6: Pesos relativos da interação entre a escolaridade e o gênero/sexo sobre a aspiração de /v/

\section{CONCLUSÕES}

A realização variável do fonema /v/ é um tema pouco recorrente nas pesquisas sociolinguísticas no português do Brasil. No entanto, é facilmente percebida a aspiração de /v/, no Ceará, ainda mais no falar fortalezense, e, por isso, decidimos estudar este fenômeno.

Os resultados obtidos revelaram que: as vogais [e)] e [a] são fortes aliadas da aspiração, tanto no contexto fonológico precedente quanto no contexto seguinte; as pós-tônicas favorecem a regra; a locução interjetiva "Ave Maria!" favorece o uso quase categórico do fenômeno e os verbos também beneficiam a variante aspirada; a menor escolaridade (de 0 a 4 anos) atua positivamente sobre a regra; os mais idosos (a partir dos 50 anos) agem no sentido de favorecer a aspiração; quanto mais frequente, maior será a possibilidade de um termo apresentar a variante aspirada; o DID favorece, discretamente, a regra; os homens são aliados da aspiração, embora de forma tímida.

Fazendo a interação entre as variáveis escolaridade e faixa etária, verificamos que os mais idosos, mesmo quando apresentam mais escolaridade, continuam favorecendo a forma aspirada. Assim, como o resultado geral favorece, principalmente, os mais idosos com menor escolaridade, afirmamos que há indícios de uma mudança em progresso, visto que a tendência é de que todas as faixas etárias, inclusive a dos mais idosos, adquiram maior escolaridade - contanto que todas as faixas avancem nos estudos. 
A interação entre faixa etária e gênero/sexo revelou que as mulheres, quando estão entre os 26 e 49 anos de idade, são aliadas da aspiração $(0,580)$, mas só elas favorecem a variante aspirada nesta faixa etária. Os homens, somente quando idosos $(0,613)$, favorecem o fenômeno. E a interação entre escolaridade e gênero/sexo revelou que os homens só favorecem o uso da regra se tiverem pouca escolaridade. Já as mulheres, ao contrário do que vimos antes de fazermos a interação, quando possuem de 0 a 4 anos de escolaridade, também são favorecedoras da aspiração.

Portanto, com base nessas variáveis linguísticas e sociais, observamos que o fenômeno, entre os informantes fortalezenses, apresentou alguns resultados diferentes dos observados em outras cidades onde o fenômeno foi estudado (Salvador e João Pessoa), demonstrando, dessa forma, que, em cada uma delas, esse processo encontra-se em diferentes estágios de implementação. Devido à escassez de trabalhos sobre esse fenômeno, não foi possível fazermos um retrato do que acontece com a aspiração do /v/ em outros dialetos do território nacional. Por isso, esperamos que outros pesquisadores possam investigá-lo em outras localidades.

Com base nos resultados apresentados aqui, podemos afirmar que a aspiração de /v/ seja uma das peculiaridades do falar fortalezense, que enriquece os elementos socioculturais que caracterizam esta comunidade. Ressaltamos ainda que um teste de atitudes, a exemplo do que fez Roncarati e Uchoa (1988), deva ser aplicado, tanto entre os informantes sem nível universitário quanto com aqueles que possuem esse grau, a fim de verificarmos o nível de estigmatização em que esse fenômeno se encontra: entre os próprios fortalezenses residentes em sua cidade natal, entre os fortalezenses que já moram há muito tempo fora de Fortaleza e entre os migrantes de outras regiōes (especialmente do Sul e Sudeste do Brasil) que vivem nesta cidade.

\section{NOTAS}

${ }^{1}$ A variação diatópica é aquela que se relaciona a diferenças linguísticas distribuídas no espaço físico, observáveis entre falantes de origens geográficas distintas. A variação diastrática é a que se verifica na comparação entre os modos de falar das diferentes classes sociais. (BAGNO, 2003).

${ }^{2}$ Número de ocorrências aspiradas/número total de dados da rodada. 
${ }^{3}$ Peso relativo. Para maiores informações sobre peso relativo, consultar a seção de Metodologia.

${ }^{4}$ Roncarati e Uchoa (1988) usam a expressão "distância de tonicidade”.

5 Ilustraçôes de frases para cada distância com seus pesos relativos: 0 - "\# [h]á buscar uma rôpinha" $(0,50) ; 1$ - "na ditadura ta[h]a pior que isso"; 4 - "Tinha que le[h]á pro Frifor" $(0,48) ; 3$ - "a gente apro[h]eita[h]a um horário" $(0,40) ; 2$ - "O gado $\lfloor$ h] em em cima..." (0,37). (RONCARATI; UCHOA, 1988, p. 29).

${ }^{6}$ Ilustrações de frases para cada distância com seus pesos relativos: 4 - "chega[h]a na maior." $(0,68) ; 1$ - "Se ti[h]er um poder aquisitivo $(0,61) ; 3$ - "[h]ai fazer cursinho." $(0,57) ; 5$ - "porque ta $[\mathrm{h}] \mathrm{a}$ muito cansado." $(0,55) ; 2$ - "que o velho ta $[\mathrm{h}] \mathrm{a}$ morto." $(0,49) ; 0$ - "A gente dança[h]a..." (0,15). (RONCARATI; UCHOA, 1988, p. 32).

${ }^{7}$ Roncarati e Uchoa (1988) e Roncarati (1999) e Pelicioli (2008) empregam a expressão nível de usualidade.

${ }^{8} \mathrm{O}$ difusionismo lexical privilegia o controle lexical e desloca o foco da mudança da unidade fonológica para a unidade morfo-lexical, prevendo afetamento gradual do léxico. (RONCARATI, 1999, p. 2)

${ }^{9}$ Os níveis de escolaridade não são especificados, apenas o da mulher de 46 anos, que possuía o $1^{\circ}$ grau incompleto.

${ }^{10}$ Ilustrando: ca[h]alo (interiorano) e esta[h]a (citadino e interiorano).

${ }^{11}$ Roncarati e Uchoa (1988; Roncarati, 1999) usam a expressão "relevância informacional”.

${ }^{12}$ A transcrição do exemplo está de acordo com o texto de Marques (2001).

13 "Ou seja, que não fazem parte da forma básica e significativa do vocábulo" (MARQUES, op. cit., p. 60).

${ }^{14}$ No efeito de variáveis covariantes, como a variável dimensão lexical que também reflete a frequência de uso, é preciso ter cautela ao analisamos os dados de outros autores, como o de Marques (2001), porque os itens mais frequentes tendem a ser os mais curtos. Assim, o uso de uma covariante pode mascarar o verdadeiro condicionante.

${ }^{15}$ Esse projeto, coordenado pela profa Dra Aluiza Alves de Araújo, recebeu a colaboração de quatro bolsistas do Programa de Iniciação Científica da Universidade Estadual do Ceará (UECE), além da inestimável ajuda do Prof. Dr. Kilpatrick Müller Campelo, que, na época, era professor substituto dessa universidade.

${ }^{16}$ Neste trabalho, resolvemos adotar a terminologia gênero/sexo, pois, embora consideremos "gênero" a mais adequada - visto que está relacionada ao papel social que 
homens e mulheres assumem -, quando as entrevistas do NORPOFOR foram feitas, foi dada prioridade à separação em sexo biológico dos indivíduos.

${ }^{17}$ As Secretarias Executivas Regionais (SER's) são termos que se referem a uma espécie de "subprefeituras" localizadas em Fortaleza.

${ }^{18}$ Demos preferência a esse censo, pois ele é o que condiz à realidade de Fortaleza à época das gravaçôes do NORPOFOR.

${ }^{19}$ A transcrição apresentada aproxima-se o máximo possível da fala dos informantes, mas optamos por não transcrevê-la foneticamente, para não dificultar a leitura de leitores de outras áreas (que não da Linguística).

20 "Women conform more closely than men to sociolinguistic norms that are overtly prescribed, but conform less than men when they are not." (Tradução nossa).

${ }^{21}$ Esse tempo foi menor, quando a gravação possuía menos de 40 minutos.

${ }^{22}$ Essa versão pode ser encontrada e copiada, gratuitamente, em: < http://individual. utoronto.ca/tagliamonte/ goldvarb.htm >

23 "Vum" foi a pronúncia do informante que, pelo contexto, poderia ser "vem", mas foi dito daquela forma.

${ }^{24}$ Sobre o teste de verossimilhança, Bisol e Brescancini (2002, p. 35-6) explicam que: "o likehood indica o grau de probabilidade de os dados terem sido gerados pelo modelo. Os valores probabilísticos que resultam no valor mais alto do likelihood são considerados os mais prováveis de terem sido gerados pelo modelo."

${ }^{25}$ Na pesquisa de Marques (2001), o contexto fonológico seguinte só foi selecionado pelo arquivo 2, no qual ela reuniu apenas as ocorrências de $/ \mathrm{v} /$ nos demais contextos que não incluíam o grupo /ava/.

${ }^{26}$ A autora explica desta forma o porquê da escolha desse critério: "Uma vez que a análise preliminar dos dados mostrou a irrelevância da tonicidade na própria sílaba das fricativas, resolvemos desconsiderar a questão da distância de tonicidade antecedente e posterior ao fenômeno em estudo." (CANOVAS, 1991, p. 66).

${ }^{27}$ Esse resultado parece estar incoerente com os demais que são apresentados por Roncarati e Uchoa (1988) em relação a essa mesma variável.

${ }^{28}$ Nesse teste de atitudes, não são citadas palavras com /v/ em início de palavra.

${ }^{29}$ Em Marques (2001), os resultados das variáveis sociais referem-se apenas ao arquivo onde ela reuniu as palavras que possuíam o grupo /ava/ (sendo do pretérito imperfeito ou não), pois, no outro arquivo, onde ela colocou os demais contextos de /v/, o programa não selecionou nenhuma variável social. 
${ }^{30}$ Lembramos que, na amostra desses autores, a faixa etária é dividida entre criança (uma de 10 anos), adolescentes (um de 14, outro de 15 anos), jovens (um de 21, outro de 22 e um de 24) e adultos (um de 38, dois de 40 e um de 42).

${ }^{31}$ Conforme já informado na seção 2.1, os dados do NORPOFOR foram coletados entre 2003 e 2006.

${ }^{32}$ A notação simbólica está igual à original.

${ }^{33}$ Marques (2001) apresenta apenas o gráfico da interação com valores aproximados. Esses valores são (até os oito primeiros anos de escolarização, para 50 anos de idade ou mais): 0,58 (0 ano), 0,60 (de 1 a 4 anos) e 0,57 (de 5 a 8 anos).

\section{REFERÊNCIAS}

ALENCAR, M. S. M. de. Aspectos sócio-dialetais da língua falada em Fortaleza: as realizações dos fonemas /r/ e /r/. 2007. 184 p. Tese (Doutorado em Linguística) - Programa de Pós-Graduação em Linguística, Fortaleza-CE, 2007.

ARAGÃO, M. do S. S. de. A neutralização dos fonemas /v, z, z/ no falar de Fortaleza. In: RIBEIRO, S.; COSTA, S. B. B.; CARDOSO, S. A. M. (orgs.). Dos sons às Palavras: nas trilhas da língua portuguesa. Salvador: EDUFBA, 2009, p. 187-200.

ARAÚJO, A. A. de. As vogais pretônicas no falar popular de Fortaleza: uma abordagem variacionista. 2007. 154 p. Tese (Doutorado em Linguística) - Programa de Pós-Graduação em Linguística, Fortaleza-CE, 2007.

. O projeto Norma Oral do Português Popular de Fortaleza - NORPOFOR. In: CONGRESSO NACIONAL DE LINGUÍSTICA E FILOLOGIA, 15., 2011, Rio de Janeiro. Cadernos do CNLF. Rio de Janeiro: CiFEFiL, 2011, v. XV, n. 5, t. 1. p. 835-845.

ARAÚJO, L. E. S. A variável faixa etária em estudos sociolinguísticos. Revista de Estudos Linguisticos, n. 35, mai. 2007. p. 389-98.

BAGNO, M. A norma oculta: língua \& poder na sociedade brasileira. 5. ed. São Paulo: Parábola, 2003.

BISOL, L.; BRESCANCINI, C. Fonologia e variação: recortes do português brasileiro. Porto Alegre: EDIPURCS, 2002. Disponível em: <http://books.google.com. br/books?id =V51ihhlkiGMC\&pg=PA37\&lpg=PA37\&dq=\%22log+likelihood $\% 22$ \&source=bl\&ots=-qY3gGJH7f\&sig=_0wqlFRMdnlvz-akJnKIYabxp10\&hl=pt\&sa= X\&ei=ZkxRUY_9K euA0AGJr4DQBA\&redir_esc=y\#v=onepage\&q=\%22log\%20 likelihood\%22\&f=false>. Acesso em: 26 mar. 2013. 
CANOVAS, M. I. F. Variação fônica de /S/ pós-vocálico e de /v, z, z/ cabeças de sílaba, na fala de Salvador. Salvador, 1991. 168f. Dissertação (Mestrado em Língua Portuguesa). Programa de Pós-Graduação em Letras, Universidade Federal da Bahia, Salvador-BA, 1991.

CARVALHO, R. S. de. Variação do /S/ pós-vocálico na fala de Belém. Belém, 2000. 122f. Dissertação (Mestrado em Linguística) - Faculdade de Letras, Universidade Federal do Pará, Belém-PA, 2000.

CHAMBERS, J.; TRUDGILL, P. Dialetology. Cambridge: Cambridge University Press, 1998 [1980]. Disponível em: <http://books.google.com.br/books?id=9bYV43Uh Ks $s C \&$ printsec $=$ frontcover\&source $=$ gbs_ge_summary_r\&cad $=0 \# \mathrm{v}=$ onepage\&q\&f=fal se>. Acesso em 18 mar. 2013.

DÜBOIS, J. et al. Dicionário de Linguística. São Paulo: Cultrix, 1973.

GUY, G. R.; ZILLES, A. Sociolinguistica Quantitativa. São Paulo: Parábola, 2007.

KATAMBA, F. An Introduction to Phonology. London: Longman, 1996. Disponível em: $<$ http://pt.scribd.com/doc/99606110/An-Introduction-to-Phonology-Learning-Abo ut-Language-KATAMBA>. Acesso em 15 dez. 2012.

LABOV, W. The social motivation of sound change. Word, 19: 273-307, 1963. In: - Padrões Sociolinguísticos. Trad. M. Bagno; M. Marta P. Scherre; Caroline R. Cardoso. São Paulo: Parábola Editorial, 2008.

. Sociolinguistics Patterns. Philadelphia: University of Pennsylvania, 1972 [ed. Br.: 2008. Padrôes Sociolinguisticos. Trad. M. Bagno; M. Marta P. Scherre \& Caroline R. Cardoso. São Paulo: Parábola Editorial, 2008.

.Principles of linguistic change: internal factors. Vol. 1. Oxford: Blackwell Publishers, 1994.

Principles of linguistic change: social factors. Vol. 2. Malden, Massachussets/ Oxford: Blackwell, 2001.

MARQUES, S. M. O. A produção variável do fonema $/ v /$ em João Pessoa. João Pessoa, 2001. 96f. Dissertação (Mestrado em Linguística). Programa de Pós-Graduação em Linguística, Universidade Federal da Paraíba, João Pessoa-PB, 2001.

MATOS, A. M.; NETO, A. C. Opulência e Miséria nos Bairros de Fortaleza. Scripta Nova: Revista electrónica de geografía y ciencias sociales. Barcelona: Universidad de Barcelona, 1 de agosto de 2003, vol. VII, núm. 146(030). < http://www.ub.es/geocrit/ sn/sn-146(030).htm > . Acesso em: 05 abr. 2013.

MONTEIRO, J. L. Para compreender Labov. Petrópolis, RJ: Vozes, 2000. 
NARO, A. J.. Modelos quantitativos e tratamento estatístico. In: MOLLICA, M. C.; BRAGA, M. L. (orgs.). Introdução à sociolinguística: o tratamento da variação. 2 ed. São Paulo: Contexto, 2004. p. 15-25.

OLIVEIRA e SILVA, G. M. Coleta de dados. In: MOLLICA, M. C.; BRAGA, M. L. (orgs.). Introdução a Sociolinguística variacionista. 2. ed. São Paulo: Contexto, 2004. p. 117-133.

PAIVA, M. da C. de. A variável gênero/sexo. In: MOLLICA, M. C.; BRAGA, M. L. (orgs.). Introdução à sociolinguística: o tratamento da variação. 2 ed. São Paulo: Contexto, 2004. p. 33-42.

PELICIOLI, R. A rênti tarra em carra mermo: a aspiração de fricativas na fala de Salvador. Salvador-BA, 2008. 48 f. Monografia (Graduação em Letras Vernáculas). Universidade Federal da Bahia, Salvador-BA, 2008.

PINTZUK, Susan. VARBRUL programs. Tradução de Ivone Isidoro Pinto, revisão de Maria Thereza Gomes Fioreti e Maria Marta Pereira Scherre (coord.) Original inglês. Inédito. 1988.

RONCARATI, C. N.; UCHOA, J. A. C. Enfraquecimento das fricativas sonoras. In: __ ALMEIDA, M. R.; ARAÚJO, M. F. Projeto Dialetos Sociais Cearenses. Fortaleza: UFC, 1988.

- Variação fonológica e morfossintática na fala cearense. In: JORNADA DE ESTUDOS LINGUÍSTICOS DO GELNE, 17, 1999, Fortaleza. Anais... Fortaleza: UFC, 1999. p. 1-12.

SANKOF, D.; TAGLIAMONTE, S. A.; SMITH, E. Goldvarb X: a multivariate analysis application. Toronto: Department of Linguistics; Ottawa: Department of Mathematics, 2005. Disponível em: <http://individual.utoronto.ca/tagliamonte/ goldvarb.htm>. Acesso em 10 dez. 2012.

SCHERRE, M. M. P. Introdução ao Pacote VARBRUL para microcomputadores. Brasília, UNB, 1993. 